\title{
Telephone consultation and triage: effects on health care use and patient satisfaction (Review)
}

\author{
Bunn F, Byrne G, Kendall S
}

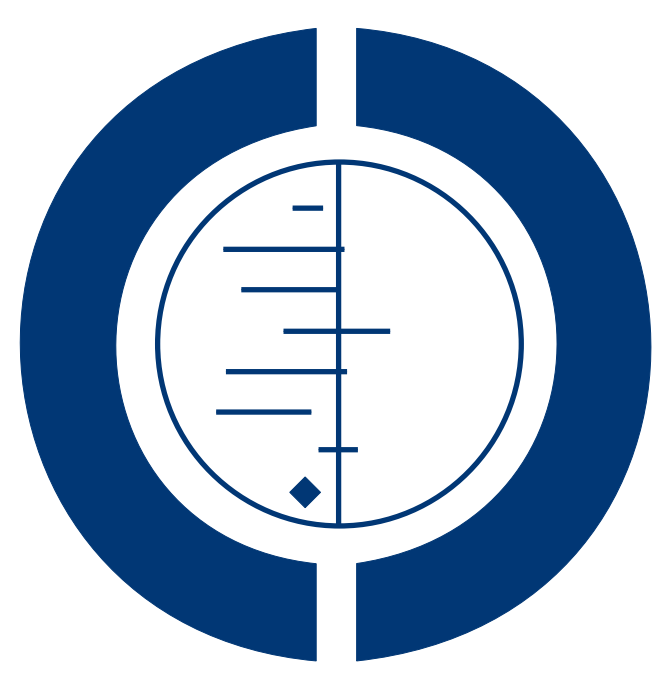

\section{THE COCHRANE COLLABORATION $^{\circledR}$}

This is a reprint of a Cochrane review, prepared and maintained by The Cochrane Collaboration and published in The Cochrane Library 2009, Issue 1

http://www.thecochranelibrary.com

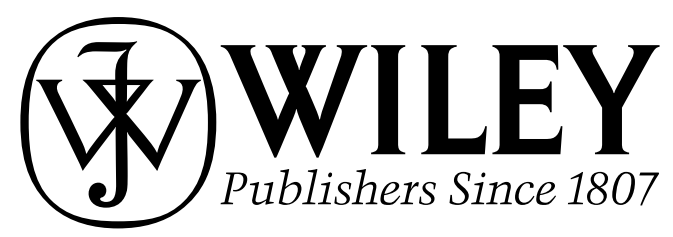

Telephone consultation and triage: effects on health care use and patient satisfaction (Review)

Copyright $\odot 2009$ The Cochrane Collaboration. Published by John Wiley \& Sons, Ltd. 
TABLE OF CONTENTS

HEADER . . . . . . . . . . . . . . . . . . . . . . . . . . . . . . . . . . . . 1

ABSTRACT . . . . . . . . . . . . . . . . . . . . . . . . . . . . . . . . . . . . . . . . . . . . . . .

PLAIN LANGUAGE SUMMARY . . . . . . . . . . . . . . . . . . . . . . . . . . . . . . . . . . . 2

BACKGROUND . . . . . . . . . . . . . . . . . . . . . . . . . . . . . . . . . . . . . .

OBJECTIVES . . . . . . . . . . . . . . . . . . . . . . . . . . . . . . . . . . . . . .

METHODS . . . . . . . . . . . . . . . . . . . . . . . . . . . . . . . . . . . . . .

RESULTS . . . . . . . . . . . . . . . . . . . . . . . . . . . . . . . . . . . . . 5

DISCUSSION . . . . . . . . . . . . . . . . . . . . . . . . . . . . . . . . . . . . . 8

AUTHORS' CONCLUSIONS . . . . . . . . . . . . . . . . . . . . . . . . . . . . . . . . . . . . . . 9

ACKNOWLEDGEMENTS . . . . . . . . . . . . . . . . . . . . . . . . . . . . . . . . . . 9

REFERENCES . . . . . . . . . . . . . . . . . . . . . . . . . . . . . . . . . . . . . . 9

CHARACTERISTICS OF STUDIES . . . . . . . . . . . . . . . . . . . . . . . . . . . . . . . . . . . . .

DATA AND ANALYSES . . . . . . . . . . . . . . . . . . . . . . . . . . . . . . . . . . . . . . 21

ADDITIONAL TABLES . . . . . . . . . . . . . . . . . . . . . . . . . . . . . . . . . . . . . . . . . . . .

WHAT'S NEW . . . . . . . . . . . . . . . . . . . . . . . . . . . . . . . . . . . . . 34

HISTORY . . . . . . . . . . . . . . . . . . . . . . . . . . . . . . . . . . . . . 35

CONTRIBUTIONS OF AUTHORS . . . . . . . . . . . . . . . . . . . . . . . . . . . . . . . . . . . . . . . . . . . .

DECLARATIONS OF INTEREST . . . . . . . . . . . . . . . . . . . . . . . . . . . . . . . 35

SOURCES OF SUPPORT . . . . . . . . . . . . . . . . . . . . . . . . . . . . . . . . . . . . . . .

NOTES . . . . . . . . . . . . . . . . . . . . . . . . . . . . . . . . . . . . . . . . . 36

INDEX TERMS . . . . . . . . . . . . . . . . . . . . . . . . . . . . . . . . . . . . 36

Telephone consultation and triage: effects on health care use and patient satisfaction (Review)

Copyright $\odot 2009$ The Cochrane Collaboration. Published by John Wiley \& Sons, Ltd. 


\title{
[Intervention Review]
}

\section{Telephone consultation and triage: effects on health care use and patient satisfaction}

\author{
Frances Bunn ${ }^{1}$, Geraldine Byrne ${ }^{2}$, Sally Kendall ${ }^{3}$ \\ ${ }^{1}$ Centre for Research in Primary and Community Care, University of Hertfordshire, Hatfield, UK. ${ }^{2}$ Department of Health and Human \\ Sciences, University of Hertfordshire, Hatfield, UK. ${ }^{3}$ Centre for Research in Primary and Community Care (CRIPACC), University \\ of Hertfordshire, Hatfield, UK
}

Contact address: Frances Bunn, Centre for Research in Primary and Community Care, University of Hertfordshire, College Lane, Hatfield, Hertfordshire, AL10 9PN, UK. f.bunn@herts.ac.uk.

Editorial group: Cochrane Effective Practice and Organisation of Care Group.

Publication status and date: Edited (no change to conclusions), published in Issue 1, 2009.

Review content assessed as up-to-date: 14 February 2008.

Citation: Bunn F, Byrne G, Kendall S. Telephone consultation and triage: effects on health care use and patient satisfaction. Cochrane Database of Systematic Reviews 2004, Issue 3. Art. No.: CD004180. DOI: 10.1002/14651858.CD004180.pub2.

Copyright (C) 2009 The Cochrane Collaboration. Published by John Wiley \& Sons, Ltd.

\begin{abstract}
A B S T R A C T
Background

Telephone consultation is the process where calls are received, assessed and managed by giving advice or by referral to a more appropriate service. In recent years there has been a growth in telephone consultation developed, in part, as a response to increased demand for general practitioner (GP) and accident and emergency (A\&E) department care.
\end{abstract}

\section{Objectives}

To assess the effects of telephone consultation on safety, service usage and patient satisfaction and to compare telephone consultation by different health care professionals.

\section{Search methods}

We searched the Cochrane Central Register of Controlled Trials, the specialised register of the Cochrane Effective Practice and Organisation of Care (EPOC) group, PubMed, EMBASE, CINAHL, SIGLE, and the National Research Register. We checked reference lists of identified studies and review articles and contacted experts in the field. The search was not restricted by language or publication status. The searches were updated in 2007 and no new studies were found.

\section{Selection criteria}

Randomised controlled trials (RCTs), controlled studies, controlled before/after studies (CBAs) and interrupted time series (ITSs) of telephone consultation or triage in a general health care setting. Disease specific phone lines were excluded.

\section{Data collection and analysis}

Two review authors independently screened studies for inclusion in the review, extracted data and assessed study quality. Data were collected on adverse events, service usage, cost and patient satisfaction. Due to heterogeneity we did not pool studies in a meta-analysis and instead present a narrative summary of the findings.

Telephone consultation and triage: effects on health care use and patient satisfaction (Review)

Copyright ( 2009 The Cochrane Collaboration. Published by John Wiley \& Sons, Ltd. 


\section{Main results}

Nine studies met our inclusion criteria, five RCTs, one CCT and three ITSs. Six studies compared telephone consultation versus normal care; four by a doctor, one by a nurse and one by a clinic clerk. Three studies compared telephone consultation by different types of health care workers; two compared nurses with doctors and one compared health assistants with doctors or nurses. Three of five studies found a decrease in visits to GP's but two found a significant increase in return consultations. In general at least $50 \%$ of calls were handled by telephone advice alone. Seven studies looked at accident and emergency department visits, six showed no difference between the groups and one, of nurse telephone consultation, found an increase in visits. Two studies reported deaths and found no difference between nurse telephone triage and normal care.

\section{Authors' conclusions}

Telephone consultation appears to reduce the number of surgery contacts and out-of-hours visits by general practitioners. However, questions remain about its affect on service use and further rigorous evaluation is needed with emphasis on service use, safety, cost and patient satisfaction.

\section{PLAIN LANGUAGESUMMARY}

\section{Telephone consultation and triage: effects on health care use and patient satisfaction}

Visits to emergency departments and family doctors have increased. One possible way to decrease the demands is to provide telephone helplines, hotlines or consultations. People can speak with health care professionals, such as doctors and nurses, on the telephone and receive medical advice or a referral to an appropriate health service. Nine studies were found and analysed to determine whether telephone consultation was safe and effective. In general, at least half of the calls were handled by telephone only (without the need for face-to-face visits). It was found that telephone consultation appears to decrease the number of immediate visits to doctors and does not appear to increase visits to emergency departments. It is still unclear though, whether it is just delaying visits to a later time. Telephone consultation also appears to be safe and people were just as satisfied using the telephone as going to see someone face-to-face. There are still questions about its effectiveness and more research into the use, cost, safety and satisfaction of telephone consultation is needed.

\section{B A C K G R O U N D}

In recent years there has been an increase in the use of telephone consultation and triage; the process where calls, from people with a health care problem, are received, assessed and managed by giving advice or by referral to a more appropriate service (Lattimer 1996). This growth has been international and includes systems in Australia (Turner 2002), Denmark (Christensen 1998), New Zealand (St George 2001), Sweden (Marklund 1989), Canada (Lafrance 2002), the United States (USA) (Barber 2000), and the United Kingdom (GBR) (DOH 1997). These systems, in general, aim either to help with the provision of out of hours care, manage demand for care, or provide an additional source of help and advice that is not limited to out of hours care alone.

One impetus for the development of telephone consultation is to reduce the burden on general practitioners (GPs) and accident and emergency (A\&E) departments. A\&E attendances in the UK have increased (Audit Commission), as has demand for the service of general practitioners (GPs), although it has been estimated that more than half of out of hours calls can be handled by telephone advice alone (Christensen 1998; Dale 1998; Marsh 1987). To date relatively little information exists on whether telephone consultation reduces pressure on other services. In Denmark demand for home visits fell by $28 \%$ after the introduction of telephone consultation by doctors (Christensen 1998). In the UK there was a small decrease in GP out of hours contacts, though no significant decrease in the use of A\&E departments or ambulance services after the introduction of National Health Service (NHS) Direct (Munro 2000b).

Although some telephone consultation is done by doctors ( Christensen 1998), much is now done by qualified nurses using computer based clinical decision support systems. This reflects changes in the role of the nurse in recent years and the move towards nurses undertaking some tasks previously done by doctors. One of the largest telephone consultation systems in operation is NHS Direct in the UK. This is a 24 hour nurse-led telephone 
advice system, based in England, which aims to help callers selfmanage problems and reduce unnecessary demands on other NHS services (Calman 1997; DOH 1997).

Caller satisfaction with NHS Direct has been found to be high (Munro 2000a; O'Cathain 2000). However, it has been argued that older people, ethnic minorities, and other disadvantaged groups under use the service, and that it has not decreased, and may in fact have increased, the burden on other health care services (George 2002). Other concerns about telephone consultation include the quality and safety of advice given (Verdie 1989; Edwards 1994; Salk 1998); although, more recent research has found it safe and effective (SWOOP 1997; Lattimer 1998; Poole 1993). In an attempt to clarify the situation we conducted a systematic review of telephone consultation and triage services to assess their effect on safety, satisfaction and service usage.

\section{O B JECT IVES}

1. To assess the effects of all telephone consultation and triage services on safety, service usage, and patient satisfaction in comparison with no telephone consultation.

2. To compare effects on caller safety, service usage, and patient satisfaction of telephone consultation led by different groups of health care workers (e.g. nurse-led versus doctor-led telephone consultation.

3. To compare effects on caller safety, service usage, and patient satisfaction, of nurse telephone consultation with and without computer assisted algorithms.

4. To compare effects, on caller safety, service usage, and patient satisfaction, of telephone consultation with follow on care versus telephone consultation where no face-to-face service is offered (e.g. doctors surgery versus an advice line such as NHS Direct).

\section{METHODS}

\section{Criteria for considering studies for this review}

\section{Types of studies}

We included Randomised controlled trials (RCTs), non-randomised controlled trials, controlled before/after Studies (CBAs) and interrupted time series (ITSs). For definitions see the Glossary on the Effective Practice and Organisation of Care (EPOC) module (See EDITORIAL INFORMATION under GROUP DETAILS for GLOSSARY).

\section{Types of participants}

Populations and areas with potential access to telephone consultation lines.

\section{Types of interventions}

All designated telephone consultation systems where patients calls are received, assessed and managed by giving advice or by referral to a more appropriate service. This included those with and without computer based clinical decision support systems. Although initially we felt there might be a distinction between telephone consultation and telephone triage services we found that the terms were used interchangeably. Therefore, throughout the review, the term 'telephone consultation' will be used to encompass both consultation and triage.

The comparisons of interest were:

Telephone consultation (by any health care professional) followed by face-to-face consultation if appropriate versus normal care (e.g. face-to- face contact alone).

Telephone consultation where no face-to-face service is offered (e.g. NHS Direct) versus normal care (e.g. face-to-face contact alone).

Telephone consultation by one health care professional group versus telephone consultation by another professional group or health care worker (e.g. nurse-led telephone consultation versus doctorled telephone consultation).

We excluded the following interventions:

Telephone consultations not done as part of a designated telephone consultation system (e.g. telephone advice given as part of GPs usual work).

Phone lines aimed at one specific illness (e.g. diabetes), or only at self help or support (e.g. smoking cessation, weight control). Disease specific phone lines are excluded because they are likely to be information giving services rather than focusing on consultation. In addition it would make the review too diverse and it would be difficult to pre-specify all the disease specific outcomes of importance.

Telephone consultation not given directly to the patient or carer.

\section{Types of outcome measures}

Visits to A\&E departments and GPs' surgeries. Home visits by GPs/deputising services within normal hours. Out-of-hours contacts.

Number of calls handled by telephone advice alone (e.g. no referral to other health care professional/ face to face contact).

Unplanned hospital admissions.

Mortality rates.

Adverse events.

Patient and carer satisfaction.

Patient quality of life.

Health care professionals attitudes/satisfaction. 
Cost to health care system and cost to patient.

\section{Search methods for identification of studies}

We searched for published and unpublished studies using the following databases: Cochrane Central Register of Controlled Trials (The Cochrane Library Issue 1 2003), EPOC specialised register (March 2003), PubMed (1966-February 2003), EMBASE (February 2003), CINAHL (1983-February 2003), SIGLE (System for Information on Grey Literature) (1980-February 2003), and the National Research Register (a database of ongoing and recently completed research projects funded by the UK National Health Service) (Issue 2 2003). Initially we ran the search including methodological search terms but this strategy appeared to miss studies. We, therefore, re-ran an adapted version of the search without methodological terms and combined the results from the two searches. The search terms used can be seen below. We also checked reference lists of identified studies and review articles, and contacted experts in the field. There were no language restrictions. The searches were updated in July 2007 but no new studies were found.

The MEDLINE strategy for the update is detailed below. The other updated searches and the searches from the first version of this review are available in the Additional tables (Table 1and Table 2).

Database: Ovid MEDLINE(R) <1950 to July Week 3 2007>

Search Strategy:

\section{$-$}

1 Triage/

2 Hotlines/

3 (triage or helpline? or hotline?).tw.

4 Family Practice/og [Organization \& Administration]

5 Emergency Medicine/og [Organization \& Administration]

6 or/ $1-5$

7 (telephone or phone).tw.

86 and 7

9 ((telephone or phone) adj consultation?).tw.

10 ((telephone or phone) adj triage).tw.

11 NHS direct.tw.

12 or/ $8-11$

13 randomized controlled trial.pt.

14 controlled clinical trial.pt.

15 intervention studies/

16 experiment\$.tw.

17 (time adj series).tw.

18 comparative study.pt.

19 random\$.tw.

20 impact.tw.

21 intervention?.tw.

22 controlled before.tw.

23 evaluation studies/
24 evaluat\$.tw.

25 or/ $13-24$

26 (pre test or pretest or post test or posttest).tw.

27 control\$.tw.

2826 and 27

2925 or 28

$30 \mathrm{animal} /$

31 human/

3230 not (30 and 31)

3329 not 32

3412 and 33

35 limit 34 to review

3634 not 35

37 meta-analysis.pt.

3836 not 37

39 limit 38 to $y r=“ 2003-2007 ”$

\section{Data collection and analysis}

\section{Trial identification}

Two review authors independently examined the title and abstract of citations identified by the electronic search and reports of possibly relevant trials identified by either were retrieved in full. Two review authors independently applied the selection criteria and extracted data, resolving disagreements by discussion.

\section{Quality assessment}

Two reviewers independently extracted data and assessed the quality of studies using a modified version of the EPOC data collection checklist (see EDITORIAL INFORMATION under GROUP DETAILS for METHODS USED IN REVIEWS). We compared quality assessments and resolved differences by discussion. For randomised controlled trials we collected information on allocation concealment, loss to follow up, blinding of outcome assessment, baseline measurement and reliability of primary outcome measure. For non-randomised studies we collected information on whether outcome assessment was blinded, the completeness of the data set and the reliability of the primary outcome measures. For ITSs we also assessed whether there were sufficient data collection points, if the intervention was independent of other changes, if a formal test for trend using appropriate method was reported and if the intervention was likely to affect data collection. Studies were not given overall scores as the use of summary scores from quality scales is not recommended (Juni 1999).

\section{Data extraction}

Two review authors independently extracted information on the following: methodological quality of studies, unit of allocation and analysis, number of patients, type of participants, outcomes, intervention and length of follow up. Data extracted on the intervention included the comparison, setting, training of staff, description of staffing of the service, whether algorithms or computer 
based clinical decision support systems were used, and hours the service covered.

\section{Analysis}

Due to heterogeneity in study design, interventions, outcomes and participating health professionals we did not pool studies in a metaanalysis. Instead a narrative and tabular summary of findings is presented and, where possible, an assessment made on the quality, size of the effect observed and statistical significance of the studies. Studies are grouped in tables according to the outcome. For each study where possible we have reported the main results in natural units in the results table and post-intervention differences and $95 \%$ confidence intervals or $\mathrm{P}$ values. For interrupted time series where possible we have calculated a change in the level of outcome at the first point after the introduction of the intervention, and estimated a change in the slopes of the regression line (calculated as post-intervention minus pre-intervention slope).

\section{RES U L T S}

\section{Description of studies}

See: Characteristics of included studies; Characteristics of excluded studies; Characteristics of ongoing studies.

For more information about individual studies see 'Table of included studies'.

We found nine studies, five RCTs (Darnell 1985; Lattimer 1998; McKinstry 2002; Stirewalt 1982; Thompson 1999), one CCT, where patients were allocated to groups in alternate weeks, (Strasser 1979) and three ITSs (Jiwa 2002; Richards 2002; Vedsted 2001), one of which (Vedsted 2001) was a population based study. Two of the RCTs (Lattimer 1998; Thompson 1999) were parallel trials using the same methodology. Six studies compared telephone consultation with standard management that did not include telephone consultation. Of those four evaluated telephone consultation by a doctor (Darnell 1985; Jiwa 2002; McKinstry 2002; Vedsted 2001), one by a nurse (Richards 2002), and one by a clinic clerk (Stirewalt 1982). In one of those studies (Darnell 1985) use of the system was very low with only $8 \%$ of eligible patients using the telephone line. Three studies compared telephone consultation by one type of health care worker with another. Two RCTs compared nurse telephone consultation with telephone consultation by a doctor in an out-of-hours deputising service (Lattimer 1998; Thompson 1999) and one CCT compared telephone consultation by a health assistant with telephone advice from a doctor or a nurse (Strasser 1979).

Six studies were set in primary care (Jiwa 2002; Lattimer 1998; McKinstry 2002; Richards 2002; Thompson 1999; Vedsted 2001), two in medical centres (Darnell 1985; Stirewalt 1982), and one in A\&E (Strasser 1979). Four studies looked at out of hours care (Darnell 1985; Lattimer 1998; Thompson 1999; Vedsted 2001).
In all the studies using a nurse or other health care worker to deliver telephone consultation algorithms or protocols were used. The two earliest studies (Strasser 1979; Stirewalt 1982) looked at the use of other health care workers but more recent studies have concentrated on doctors or nurses delivering telephone consultations. Five studies were done in the UK (Jiwa 2002; Lattimer 1998; McKinstry 2002; Richards 2002; Thompson 1999), three in the USA (Darnell 1985; Stirewalt 1982; Strasser 1979) and one in Denmark (Vedsted 2001).

Studies varied in size. Of the RCTs and CCT the largest (Lattimer 1998 ) included a GP co-operative of 55 GPs and dealt with a total of 14,492 calls. The number of calls in the others was 667 (Darnell 1985), 561 (Stirewalt 1982), 388 (McKinstry 2002), 338 (Strasser 1979) and 223 (Thompson 1999). Of the ITSs the largest (Vedsted 2001) covered a time period of nine years and a population of 630,000 , and the smaller trials covered 12 months with a study population of 7200 (Jiwa 2002), and nine months with a study population of 20,800 (Richards 2002).

\section{Risk of bias in included studies}

More information about individual studies can be seen in the table of included studies. All studies had methodological weaknesses according to the EPOC data collection checklist. For two trials additional information was obtained from the authors (Jiwa 2002, Richards 2002).

\section{RCTs/CCT}

Allocation concealment

Allocation concealment was adequate in three trials (Lattimer 1998; McKinstry 2002; Thompson 1999), not done in one (Strasser 1979), and unclear in two (Darnell 1985; Stirewalt 1982).

\section{Follow up}

Four studies report adequate follow up of patients (Lattimer 1998; McKinstry 2002; Stirewalt 1982; Thompson 1999) but in the other two (Darnell 1985; Strasser 1979) it was unclear.

Assessment of primary outcome blinded

All six trials were judged to have blinded assessment of the primary outcome (Darnell 1985; Lattimer 1998;McKinstry 2002; Stirewalt 1982; Strasser 1979; Thompson 1999) because the primary outcome measure was objective.

Baseline measurement

Only two studies (Darnell 1985; Stirewalt 1982) reported that a baseline measurement of the outcome had been done.

Primary outcome measure reliable

Three studies (Lattimer 1998; Stirewalt 1982; Thompson 1999) used a reliable outcome measure for the primary outcome (e.g. data obtained from automated system), in the rest it was unclear. Protection against contamination

In one trial (Darnell 1985) it was unlikely that communication between the control and intervention groups could occur. We, there- 
fore, judged that it was protected against contamination. However, in the other five there was the possibility of contamination as the control group could receive the intervention (and in many cases be randomised twice).

Unit of allocation and analysis

In one study there was a unit of analysis error (Darnell 1985). The unit of allocation was practice teams and unit of analysis was individual patients. Therefore, as confidence intervals are likely to be too narrow and P-values too small, we have reported the effect size but no measure of statistical significance.

Power calculation

Only two trials (Lattimer 1998; McKinstry 2002) had done power calculations. One trial (Thompson 1999) was underpowered for the majority of the outcomes measured.

ITSs

Intervention independent of other changes

In two studies (Richards 2002; Jiwa 2002) the author confirmed that there were no other changes in practice and policy that might have affected the handling of appointments. In the other (Vedsted 2001) the intervention was judged to be independent of other changes.

Data analysed appropriately

In two of the studies the data were analysed appropriately. One (Jiwa 2002) used autoregression analysis to allow for serial correlation and linear regression and one (Richards 2002) used a multivariate time series analysis. However, in the third (Vedsted 2001) they did not look for serial correlation and the analysis was redone using time series regression techniques.

Reason for number of point pre and post intervention given

None of the studies gave the reason for the number of time points chosen.

Was the shape of the intervention specified

In only one study (Vedsted 2001) was the shape of the intervention specified.

Protection against detection bias

In two studies (Jiwa 2002; Richards 2002) we judged that the intervention was unlikely to affect data collection but in the other (Vedsted 2001) there was a change from manual to electronic recording after the start of the intervention.

Blinded assessment of primary outcome(s)

In all three studies the primary outcome variable was objective and so assessment was judged to be blinded.

Completeness of data set

All three studies were judged to have complete data sets.

Reliable primary outcome measure(s)

Two studies used reliable primary outcome measures (Jiwa 2002; Richards 2002). In one (Jiwa 2002) two researchers independently collected data and in the other (Richards 2002) data collected by an individual were checked against electronic data. In the other study (Vedsted 2001) prior to the intervention data were collected manually but afterwards this changed to automatic electronic registration.

\section{Effects of interventions}

We screened 3437 records from the electronic database searches of which 62 were considered to be potentially relevant based on the title or abstract. After full text review, eleven studies were judged to meet the inclusion criteria. However, two (Dale 2003; Lee 2002) did not present relevant data and were excluded leaving nine studies. When interpreting the data, it should be noted that for many of the outcomes equivalence was regarded as desirable. Researchers were normally concerned to determine whether telephone consultation was as safe and effective as existing services. Numerical data are presented in 'other data' tables.

1. Telephone consultation versus normal care ( 01 other data tables)

Six studies compared telephone consultation with standard management that did not include telephone consultation. Four evaluated telephone consultation by a doctor (Darnell 1985; Jiwa 2002; McKinstry 2002; Vedsted 2001), one by a nurse (Richards 2002), and one by a clinic clerk (Stirewalt 1982). Three were RCTs (randomised controlled trials) (Darnell 1985; McKinstry 2002; Stirewalt 1982) and three were ITSs (interrupted time series) (Jiwa 2002; Richards 2002; Vedsted 2001).

\section{Routine general practitioner appointments}

Three studies reported the number of appointments at GP surgeries. The RCT, of telephone consultation by a doctor (McKinstry 2002) found that although same-day appointments were decreased there was an increase in GP visits in the two week follow-up period (mean difference of 0.2 (95\% CI 0.0 to 0.3 ) $\mathrm{P}=0.01$ ). In the ITS of nurse telephone triage (Richards 2002) there was also a significant reduction in immediate GP appointments (RD - 0.23 (95\% CI -0.26 to -0.20$)$ ) but a subsequent increase in the number of return consultations (mean difference 0.32 (95\% CI 0.22 to $0.41)(\mathrm{P}=<0.001))$. The other ITS of telephone consultation by a doctor (Jiwa 2002) found a significant reduction of $39 \%$ in GP visits $(\mathrm{P}=<0.001)$.

\section{Calls handled by telephone advice alone}

Three studies reported the number of calls managed by telephone consultation alone. In the RCT (McKinstry 2002) doctors handled $72.2 \%$ of the calls by telephone advice alone. Of the ITSs, in one (Richards 2002) nurses handled $25.5 \%$ of calls by telephone advice and in the other (Jiwa 2002) doctors dealt with $29.3 \%$ of calls by telephone advice alone and a further $22.4 \%$ of patients were offered a prescription without a face-to-face consultation.

\section{Visits to $A$ \& $E$}

Four studies looked at the number of visits to A\&E departments. In the three studies of telephone consultation by a doctor two RCTs (Darnell 1985; McKinstry 2002) found no significant difference between telephone consultation and face to face appointments 
(range difference -0.04-0). The other study, an ITS, (Vedsted 2001) found a significant increase in contact rates with $A \& E$ but, given the constant rise in contact rates, the authors performed a regression model which showed the increase was not statistically significant. The other ITS, of nurse telephone consultation, (Richards 2002) found a significant rise in number of visits to $A \&$ E, with a mean difference of 0.023 (95\% CI 0.015 to 0.032$) \mathrm{P}=$ 0.001 .

\section{Hospital admissions}

Two RCTs reported numbers of hospital admissions (Darnell 1985; Stirewalt 1982). The trial of telephone consultation by doctors (Darnell 1985) found no significant difference between the intervention and control groups (adjusted risk difference at two year follow up $=0.03$ ). However, the trial using clinic clerks to run a specialised telephone service (Stirewalt 1982) found a significant reduction, in the intervention group, in hospitalisations at 12 months (mean difference $=0.17 \mathrm{P}<0.05$ ).

\section{Home visits by general practitioners}

The one ITS that reported number of home visits by a GP ( Richards 2002) found a non significant reduction in the number of visits (RD -0.02 (95\% CI -0.04 to 0.00$)$ )

\section{Out-of-hours contacts}

Two studies reported the number of out-of-hours contacts ( McKinstry 2002, Richards 2002). The RCT of telephone consultation by a doctor (McKinstry 2002) found no difference in out-of-hours contacts between the two groups (mean difference $0)$. However, the other, an ITS of nurse telephone consultation, (Richards 2002) found a significant increase in the number of outof- hours contacts in the intervention group (mean difference 0.04 (95\% CI 0.01 to 0.07 ) $\mathrm{P}=0.005$ ).

\section{Patient satisfaction}

Four studies reported patient satisfaction. Of the three RCTs one (McKinstry 2002) found no significant difference in levels of satisfaction between telephone and face to face consultations and over half of both groups said they would use telephone consultation in the future (difference $-8.4 \%$ (95\% CI $-23.1 \%$ to $6.4 \%)$ ). In the other two RCTs (Darnell 1985; Stirewalt 1982) patients in the intervention group were more satisfied. In one (Darnell 1985) 78\% of those interviewed were satisfied with length of time before the doctor responded, length of consultation and care provided. In the other (Stirewalt 1982) they used two satisfaction with care scales and found patients in the intervention group were more satisfied. This was significant at the overall multivariate level. In the ITS (Jiwa 2002) 98\% were satisfied or very satisfied with the outcome of the telephone consultation and $84 \%$ said they would be happy to receive the service again in the future. However, the satisfaction data needs to be interpreted cautiously. In one (McKinstry 2002) there was a response rate of less than $50 \%$, in another (Darnell 1985) they only collected satisfaction data on a subset of $241 \mathrm{pa}-$ tients in the intervention group and in the ITS (Jiwa 2002) there is no comparison group.

Cost
Two ITSs reported data on cost. One (Richards 2002), which did a thorough economic evaluation, found little difference in cost between the intervention and control groups (mean difference 1.48 (95\% CI - 0.19 to 3.15). In the other (Jiwa 2002), where they only looked at cost of the phone calls, they found that telephone bills increased by $26 \%$.

2. Telephone consultation by one health care professional group versus telephone consultation by another health care professional group or health care worker ( 02 other data tables) Two RCTs compared nurse telephone consultation with normal telephone triage by a doctor in an out-of-hours deputising service (Lattimer 1998; Thompson 1999) and one CCT compared telephone triage by a health assistant with telephone advice from a doctor or a nurse (Strasser 1979). Two of the studies were small (Strasser 1979; Thompson 1999), and one in particular (Thompson 1999) was underpowered for the majority of the outcomes measured.

\section{Routine general practitioner appointments}

The two RCTs of nurse telephone consultation (Lattimer 1998; Thompson 1999) reported less GP appointments in surgery in the intervention group during the trial period. However, this was only significant in one (Lattimer 1998) RD -0.10 995\% CI -0.11 to -0.09$)$.

\section{Calls handled by telephone advice alone}

In the studies comparing nurse telephone consultation with a GP deputising service at least $50 \%$ of calls were handled by telephone advice alone. In one (Lattimer 1998) 50\% of calls in both groups were handled by telephone advice alone. In the other (Thompson 1999) $59 \%$ of calls in the nurse consultation group and $62 \%$ of calls in the GP group were managed by telephone advice alone.

Visits to $A \mathcal{G} E$

All three studies found a slight increase in number of visits to A\&E in the intervention group (range $0.3 \%$ to $2 \%$ increase) but results were not significant.

\section{Hospital admissions}

The two RCTs that looked at hospital admissions (Lattimer 1998; Thompson 1999) found no significant difference between the intervention and control groups in the number of hospital admissions at $24 \mathrm{hrs}$ and three days after contact with out-of-hours service. At three days the risk difference for admissions was $(-0.01$ (95\% CI -0.02 to 0.00$)$ (Lattimer 1998) and (-0.02 (95\% CI 0.08 to 0.05 )(Thompson 1999).

\section{Out-of-hours contacts}

Both RCTs found a significant reduction in number of home visits by the deputising service. Risk differences were -0.06 (95\% CI 0.07 to -0.04 ) (Lattimer 1998 ) and -0.12 (95\% CI -0.24 to -0.11 ) (Thompson 1999).

\section{Patient satisfaction}

One RCT (Lattimer 1998) sent out questionnaires to determine patient satisfaction but because of a poor response rate they do not present the data. The CCT (Strasser 1979) reported slightly higher satisfaction for nine out of the ten satisfaction related ques- 
tions asked. However, this is not reported clearly and detailed information is not given.

\section{Cost}

In the trial with an economic evaluation (Lattimer 1998) the cost of providing nurse telephone consultation was $£ 81,237$ a year but there was a reduction in overall costs of over $£ 100,000$.

\section{Death}

The two RCTs that looked at deaths (Lattimer 1998; Thompson 1999) found no significant difference between nurse telephone triage and triage by a doctor for patients who had been in contact with the out-of-hours service within the previous seven days (RD $0(95 \%$ CI 0.00 to 0.00$))$ and (RD $0(95 \%$ CI -0.03 to 0.04$))$ respectively. However, both studies were underpowered to detect mortality.

\section{Nurse telephone consultation with and without computer assisted algorithms}

In all of the studies where telephone consultation was performed by a health care worker other than a doctor protocols or algorithms were used. Therefore, as there were no head to head comparisons with and without algorithms, we are unable to assess their effect. In addition, it would appear that the use of computer assisted algorithms for nurse telephone consultation is well established and further trials in this area are unlikely.

\section{ISCUSSIO N}

This systematic review found that telephone consultation and triage reduce immediate GP, or home, visits and that, in general, at least $50 \%$ of calls can be handled by telephone advice alone (ranging from $25.5 \%$ to $72.2 \%$ ). However, it is unclear if in some instances triage is just delaying visits as two studies (McKinstry 2002; Richards 2002) showed an increase in return consultations. We found no evidence of an increase in adverse effects or use of other services and patients were satisfied. However, variability in interventions studied, methodological quality, and lack of power in some studies, means that results should be interpreted cautiously. In addition data on some of the outcomes, in particular patient satisfaction, cost and adverse events, were reported by few of the included studies. Initially we felt there would be a distinction between telephone consultation and triage systems. However, in reality, we found that these terms were used interchangeably. The majority of studies in this review, five out of nine were set in UK General Practice.

One of the aims of this review was to compare telephone consultation by different groups of health care professionals. Only three of the included studies directly compared one group of health care worker with another (Lattimer 1998; Strasser 1979; Thompson 1999). However, the two studies comparing nurse telephone consultation with a GP deputising service (Lattimer 1998; Thompson 1999) were good quality RCTs and found nurses could reduce GP workload without an increase in adverse events. Two of the older studies (Stirewalt 1982, Strasser 1979) use unqualified staff to deliver telephone consultation and are, therefore, perhaps less relevant to present day systems where the emphasis seems to be on consultation by qualified staff. In the other included studies the type of health care professional delivering the intervention did not appear to affect outcome although one study, of nurse telephone consultation, found a small but significant increase in out-of-hours contacts and visits to $A \& E$ (Richards 2002). In all the studies of nurse telephone consultation computer algorithms were used. We were, therefore, unable to assess the effect of telephone consultation with and without computer assisted algorithms. Also although other uncontrolled studies have found high levels of satisfaction with nurse telephone consultation (Munro 2000a; O'Cathain 2000), we have no way of assessing this important outcome as none of the studies of nurse telephone consultation in this review reported it adequately.

This review supports previous estimates that at least $50 \%$ of calls can be handled by telephone advice alone (Christensen 1998; Dale 1998; Marsh 1987). In addition findings from an observational study, of the impact of NHS Direct, (Munro 2000) found that there was no decrease in the use of A\&E departments but an impact on the use of GP co-operatives, are similar to the results of this review. Although other studies have highlighted the potential for errors or mismanagement with telephone consultation (Verdie 1989; Edwards 1994; Salk 1998) few studies in this review reported adverse outcomes. However, the two that did (Lattimer 1998; Thompson 1999) found no increase in adverse events; although they were underpowered to detect mortality.

There are a number of methodological issues that could have an important bearing on the validity of these results. Publication and other selection biases are a potential threat to validity in all systematic reviews, but this is a particular problem when searching for non randomised studies. Non randomised studies are more difficult to identify than randomised ones because there is a variety of study designs, there is no standardised terminology and they may not be keyworded according to study design (Peersman 1998). Despite our efforts to identify all eligible studies, published and unpublished, we cannot exclude the possibility that some studies were missed. In addition no studies met all the methodological criteria on the EPOC checklist which may also adversely affect the validity of the results.

The increase in the use of telephone consultation is, at least partially, a response to increased workloads for GPs and attempts to manage requests for same day appointments. In addition the current UK government agenda is promoting the use of alternative technologies to improve access to health care (DOH 2000). The largest telephone consultation service within the UK is now NHS Direct which is presently staffed by qualified nurses. However, we found no controlled studies of this service that met our inclusion criteria. Therefore, although telephone consultation appears to 
have the potential to reduce GP workload, further rigorous evaluation of such systems is needed with emphasis on service use, safety, cost and patient satisfaction.

\section{AUTHORS, CONCLUSIONS}

\section{Implications for practice}

Telephone consultation can reduce the number of surgery contacts and out-of-hours visits by general practitioners and appears to be safe. However, there may be an increase in repeat visits and further evaluation is needed.

\section{Implications for research}

Although we found nine evaluations of telephone consultation, that met our inclusion criteria, there was limited data on a number of important outcomes. Therefore, further rigorous evaluation of such systems is needed with emphasis on service use, safety, cost and patient satisfaction.

\section{ACK NOW LEDGEMENTS}

With thanks to the EPOC editorial team in particular Phil Alderson, Craig Ramsay and Jeremy Grimshaw.

\section{R E F E R E N C E S}

\section{References to studies included in this review}

\section{Darnell 1985 \{published data only\}}

Darnell JC, Hiner SL, Neill PJ, Mamlin JJ, McDonald CJ, Hui SL, Tierney WM. After-hours telephone access to physicians with access to computerized medical records. Medical Care 1985;23(1):20-6.

Jiwa 2002 \{published data only\} Jiwa M, Mathers N, Campbell M. The effect of GP telephone triage on numbers seeking same-day appointments. BrJ Gen Pract 2002;52(478):390-1.

Lattimer 1998 \{published data only\}

Lattimer V. A randomised controlled trial of nurse telephone triage in out of hours primary care. University of Southampton $\mathrm{PhD}$ thesis.

Lattimer V, George S, Thompson F, Thomas E, Mullee M, et al.Safety and effectiveness of nurse telephone consultation in out of hours primary care: randomised controlled trial. BMJ 1998;317:1054-9.

Lattimer V, Sassi F, George S, Moore M, Turnbull J, Mullee $\mathrm{M}$, Smith H. Cost analysis of nurse telephone consultation in our of hours primary care: evidence from a randomised controlled trial. BMJ 2000;320:1053-7.

McKinstry 2002 \{published data only\}

McKinstry B, Walker J, Campbell C, Heaney D, Wyke $\mathrm{S}$. Telephone consultations to manage requests for sameday appointments: a randomised controlled trial in two practices. Br J Gen Pract 2002;52(477):306-10.

Richards 2002 \{published data only\} Richards DA, Meakins J, Tawfik J, Godfrey L, Dutton E, Richardson G, Russell D. Nurse telephone triage for same day appointments in general practice: multiple interrupted time series trial of effect on workload and costs. BMJ 2002; 325:1214-7.

Stirewalt 1982 \{published data only\} Stirewalt CF, Linn MW, Godoy G, Knopka F, Linn BS. Effectiveness of an ambulatory care telephone service in reducing drop-in visits and improving satisfaction with care. Med Care 1982;20(7):739-48.

Strasser 1979 \{published data only\}

Strasser P, Levy JC, Lamb GA, Rosekrans J. Controlled clinical trial of pediatric telephone protocols. Pediatrics 1979;64(5):553-7.

Thompson 1999 \{published data only\} Thompson F, George S, Lattimer V, Smith H, Moore $\mathrm{M}$, Turnbull J, et al.Overnight calls in primary care: randomised controlled trial of management using nurse telephone consultation. BMJ 1999;319(7222):1408.

Vedsted 2001 \{published data only\} Vedsted P, Christensen MB. The effect of an out-of-hours reform on attendance at casualty wards. Scand J Prim Health Care 2001;19:95-8.

\section{References to studies excluded from this review}

Christensen 1998 \{published data only\} Christensen M, Olsen F. Out of hours service in Denmark: evaluation five years after reform. BMJ 1998;316:1502-5.

Cragg 1997 \{published data only\} Cragg D, McKinley R, Roland M, Campbell S, Van F, Hastings A, et al.Comparison of out of hours care provided by patients' own general practitioners and commercial deputising services: a randomised controlled trial. I The Process of Care. BMJ 1997;314:197-9.

Dale 2003 \{published data only\}

Dale J, Higgins J, Williams S, Foster T, Snooks H, Crouch $\mathrm{R}$, et al.Computer assisted assessment and advice for "nonserious" 999 ambulance service callers: the potential impact on ambulance despatch. Emerg Med J 2003;20:178-83.

de Groot 2002 \{published data only\} de Groot R, de Haan J, Bosveld H, Nijland A, Meyboomde Jong $B$. The implementation of a call-back system reduces the doctor's workload, and improves accessibility by telephone in general practice. Family Practice 2002;19(5): 516-9. 
Elwyn 1999 \{published data only\}

Elwyn GJ, Kinnersley P, Rees J, Rees M. A nurse telephone triage system in an inner-city practice. Nursing Times 1999; 95(23): 43

Franco 1997 \{published data only\} Franco SM, Mitchell CK, Buzon RM. Primary care physician access and gatekeeping: a key to reducing emergency department use. Clin Pediatr (Phila) 1997;36 (2):63-8.

Gallagher 1998 \{published data only\}

Gallagher M, Huddart T, Henderson B. Telephone triage of acute illness by a practice nurse in general practice: outcomes of care. Brit J Gen Pract 1998;48:1141-5.

Jones 2001 \{published data only\}

Jones J, Playforth MJ. The effect of the introduction of NHD Direct on requests for telephone advice from an accident and emergency department. Emerg Med J 2001; 18:300-1.

Lee 2002 \{published data only\}

Lee TJ, Baraff LJ, Guzy J, Johnson D, Woo H. Does telephone triage delay significant medical treatment?. Arch Pediatr Adolesc Med 2003;157:635-41.

Lee TJ, Guzy J, Johnson D, Woo H, Baraff LJ. Caller satisfaction with after-hours telephone advice: nurse advice service versus on-call pediatricians. Pediatrics 2002;110(5): $865-72$.

Munro 2000 \{published data only\}

Munro J, Nicholl J, O'Cathain A, Knowles E. Impact of NHS direct on demand for immediate care: observational study. BMJ 2000;321(7254):150-3.

\section{O'Connell 2001 \{published data only\}}

O'Connell JM, Johnson DA, Stallmeyer A, Cokingtin D. A satisfaction and return-on-investment study of a nurse triage service. Am J Manag Care 2001;7:159-69.

Richards 2004 \{published data only\}

Richard D, Godfrey L, Tawfik J, Ryan M, Meakins J, et al.NHS Direct versus general practice based triage for same day appointments in primary care: cluster randomised controlled trial. BMJ 2004;329 (7469):774:Epub 2004 Sep 17.

Salk 1998 \{published data only\}

Salk ED, Schriger DL, Hubbell KA, Schwarz BL. Effect of visual clues, vital signs and protocols on triage: a prospective randomised crossover trial. Annals of Emergency Medicine 1998;32(6):655-64.

SWOOP 1997 \{published data only\}

South Wiltshire Out of Hours Project (SWOOP) Group.

Nurse telephone triage in out of hours primary care: a pilot study. BMJ 1997;314:198.

Vedsted 1999 \{published data only\}

Vedsted P, Oleson F. Effect of a reorganized after-hours family practice service on frequent attenders. Family Medicine 1999;31(4):270-275.

\section{References to ongoing studies}

Richards \{unpublished data only\}

NHS Direct versus practice based nurse telephone triage: a randomised controlled trial.. Ongoing study July 2001.

\section{Vorster \{published data only\}}

Practice based nurse telephone triage for same day patient requests.. Ongoing study Starting date of trial not provided. Contact author for more information.

\section{Additional references}

\section{Audit Commission}

Audit Commission. Review of National Findings Accident \& Emergency. The Audit Commission, UK http:// www.audit-commission.gov.uk/ 2001.

Barber 2000

Barber J, King W, Monroe K, Nichols M. Evaluation of emergency department referrals by telephone triage. Pediatrics 2000;105(4):819-21.

\section{Calman 1997}

Calman K. Developing emergency services in the community. The final report. London: NHS Executive 1997.

\section{Christensen 1998}

Christensen M, Olsen F. Out of hours service in Denmark: evaluation five years after reform. BMJ 1998;316:1502-5.

Dale 1998

Dale J, Crouch R. Primary care: nurse-led telephone triage and advice out of hours. Nursing Standard 1998;12(47): $41-5$.

\section{DOH 1997}

Department of Health. The New NHS modern, dependable. The Stationary Office 1997.

\section{DOH 2000}

The NHS Plan. DOH July 2000.

\section{Edwards 1994}

Edwards B. Telephone triage: how experienced nurses reach decisions. Journal of Advanced Nursing 1994;19:717-24.

\section{George 2002}

George S. NHS Direct audited: Customer satisfaction but at what price?. BMJ 2002;324:558-9.

\section{Juni 1999}

Juni P, Witschi A, Bloch R, Egger M. The hazards of scoring the quality of clinical trials for meta-analysis. JAMA 1999; 282:1054-60.

Lafrance 2002

Lafrance M, Leduc N. Awareness of the Info-Sante telephone service by users of urgent care services. Can J Public Health 2002;93(1):67-71.

\section{Lattimer 1996}

Lattimer V, George S. Nurse telephone triage in out of hours primary care. Prim Care Manage 1996;6:3-6.

\section{Lattimer 1998}

Lattimer V, George S, Thompson F, Thomas E, Mullee M, Turnball J, et al.Safety and effectiveness of nurse telephone 
consultation in out of hours primary care: randomised controlled trial. BMJ 1998;317:1054-9.

\section{Marklund 1989}

Marklund B, Bengtsson C. Medical advice by telephone at Swedish health centres: who calls and what are the problems?. Fam Pract 1989;6(1):42-6.

\section{Marsh 1987}

Marsh GN, Horne RA, Channing DM. A study of telephone advice in managing out-of-hours calls. $J R$ Coll Gen Pract 1987;37:301-4.

\section{Munro 2000a}

Munro J, Nicholl J, O'Cathain A, Knowles E. Impact of NHS direct on demand for immediate care: observational study. BMJ 2000;321:150-3.

\section{Munro 2000b}

Munro J, Nicholl J, O'Cathain A, Knowles E. Evaluation of NHD Direct first wave sites second interim report to the Department of Health. Medical Care Research Unit, University of Sheffield 2000.

\section{O'Cathain 2000}

O'Cathain A, Munro JF, Nicholl JP, Knowles E. How helpful is NHS Direct? Postal survey of callers. BMJ 2000; 320:1035.

\section{Peersman 1998}

Peersman G, Harden A, Oliver S, Oakley A. Reviews of effectiveness in health promotion: A report for the Department of Health, England. London. EPI-Centre 1998.

Poole 1993

Poole SR, Schmitt BD, Carruth T, Peterson-Smith A, Slusarski M. After-hours telephone coverage: the application of an area-wide telephone triage and advice system for pediatric practices. Pediatrics 1993;92(5):670-9.

\section{St George 2001}

St George IM, Cullen MJ. The Healthline pilot: call centre triage in New Zealand. N Z Med J 2001;114(1140): 429-30.

\section{Turner 2002}

Turner V, Bentley P, Hodgson S, Collard P, Drimatis R, Rabune C, Wilson A. Telephone triage in Western Australia. MJA 2002;176:100-3.

\section{Verdie 1989}

Verdie V, Paris P, Stewart R, Verdie L. Emergency Department Telephone Advice. Annals of Emergency Medicine 1989;18:278-82.

* Indicates the major publication for the study 


\section{CHARACTERISTICS OF STUDIES}

\section{Characteristics of included studies [ordered by study ID]}

\section{Darnell 1985}

\begin{tabular}{|c|c|c|}
\hline Methods & \multicolumn{2}{|c|}{$\begin{array}{l}\text { RCT } \\
\text { Concealment: NOT CLEAR } \\
\text { Follow-up: NOT CLEAR. } \\
\text { Blinded assessment of primary outcome: DONE. } \\
\text { Baseline measurement: DONE. } \\
\text { Reliable primary outcome measure: NOT CLEAR. } \\
\text { Protection against contamination: DONE } \\
\text { Power calculation: NOT DONE }\end{array}$} \\
\hline Participants & \multicolumn{2}{|c|}{$\begin{array}{l}\text { Providers - Internal medicine doctors from outpatient general medicine clinic, at inner-city hospital, } \\
\text { providing primary care to } 11,000 \text { adults making } 38,000 \text { visits yearly. } \\
\text { Participating patients - adults requiring after hours care. } \\
\text { Country - USA }\end{array}$} \\
\hline Interventions & \multicolumn{2}{|c|}{$\begin{array}{l}\text { Ia) Telephone access to } \mathrm{dr} \text { after hours (drs had no access to medical records) ( } \mathrm{n}=758 \text { patients). } \\
\text { Ib) Telephone access to } \mathrm{dr} \text { after hours ( } \mathrm{drs} \text { had access to medical records) ( } \mathrm{n}=860 \text { patients). } \\
\text { C) Usual clinical care but no telephone access to } \mathrm{dr} \text { after hours ( } \mathrm{n}=691 \text { patients) }\end{array}$} \\
\hline Outcomes & \multicolumn{2}{|l|}{$\begin{array}{l}\text { A\&E visits } \\
\text { Hospitalisations. }\end{array}$} \\
\hline Notes & \multicolumn{2}{|c|}{$\begin{array}{l}\text { Randomisation by practice team. } \\
314 \text { pts made } 467 \text { calls. } \\
\text { Less than } 8 \% \text { of eligible patients made a call during study. } \\
\text { Follow up - } 2 \text { yrs. }\end{array}$} \\
\hline \multicolumn{3}{|l|}{ Risk of bias } \\
\hline Item & Authors' judgement & Description \\
\hline Allocation concealment? & Unclear & B - Unclear \\
\hline
\end{tabular}




ITS.
July 1999- June 2000
Clearly defined point when intervention occured: DONE
Intervention independent of other changes: DONE*.
Sufficient data points before and after the intervention - DONE
Formal test for trend: DONE
Intervention unlikely to affect data collection: DONE*
Blinded assessment of primary outcome(s):
DONE (objective outcomes).
Completeness of data set - main outcomes DONE*, pt satisfaction - NOT DONE (74\% response rate)
Reliable primary outcome measure(s): DONE
Power calcuation: NOT CLEAR

\begin{tabular}{ll} 
Participants & $\begin{array}{l}\text { Providers - GPs in a group practice with, a list size of } 7200, \text { and four GPs. } \\
\text { Participating patients - patients requesting a same day appointment with their GP. } \\
\text { Country - UK }\end{array}$ \\
\hline Interventions & I) Telephone consultation with a dr $(\mathrm{n}=3680$ calls $)$ \\
\hline Outcomes & $\begin{array}{l}\text { Demand for face-to-face appointments } \\
\text { Patient satisfaction } \\
\text { Cost of telephone calls }\end{array}$ \\
\hline
\end{tabular}

Notes All patients requesting a same-day appointment were told a dr would ring them back later. Average duration of calls less than 2 mins.

2 yrs data before, 1 after.

Risk of bias

\begin{tabular}{lll}
\hline Item & Author' judgement & Description \\
\hline Allocation concealment? & Unclear & D - Not used \\
\hline
\end{tabular}

\section{Lattimer 1998}

Methods RCT.

Concealment: DONE (26 blocks of 2 weeks, one of each pair of matching out of hours periods was randomly allocated to the intervention, the other to normal service)

Follow up - DONE

Blinded assessment of primary outcomes: DONE (objective outcome).

Baseline measurement: NOT CLEAR.

Reliable primary outcome measure: DONE (management outcome), NOT CLEAR (adverse events).

Protection against contamination: NOT DONE

Power calculation: DONE.

Participants

Providers- nurses with 6 weeks specialist training. Based in GP out-of-hours co-operative covering 55 GPs, practice population of 97,000 .

Participating patients- Patients requesting out of hours care from GP.

Country- UK 


\begin{tabular}{|c|c|c|}
\hline Interventions & \multicolumn{2}{|c|}{$\begin{array}{l}\text { I) Nurse telephone consultation using computer assisted algorithms. ( } \mathrm{n}=7,184 \text { calls) } \\
\text { C) Standard practice: telephone consultation by deputising service doctor ( } \mathrm{n}=7308 \text { calls) }\end{array}$} \\
\hline Outcomes & \multicolumn{2}{|c|}{$\begin{array}{l}\text { Mortality } \\
\text { Visits to A\& E dept and surgery, home visits, unplanned hospitalisations, } \\
\text { calls handled by telephone advice alone, cost. }\end{array}$} \\
\hline Notes & \multicolumn{2}{|c|}{$\begin{array}{l}10134(10.4 \%) \text { of patients contacted the out of hours service on } 14492 \text { occasions. } \\
\text { Questionnaires on patient satisfaction were sent out but data not presented in paper due to poor response } \\
\text { rate. } \\
\text { Follow up: mortality } 7 \text { days, visits to A\&E, GP, hospitalisations at } 3 \text { and } 7 \text { days }\end{array}$} \\
\hline \multicolumn{3}{|l|}{ Risk of bias } \\
\hline Item & Authors' judgement & Description \\
\hline Allocation concealment? & Yes & A - Adequate \\
\hline
\end{tabular}

McKinstry 2002

\begin{tabular}{|c|c|}
\hline Methods & $\begin{array}{l}\text { RCT. } \\
\text { Concealment: DONE (numbered sealed envelope). } \\
\text { Follow up: resource use- DONE ( } 97.7 \%) \text {, patient satisfaction - NOT DONE (47.9\%) } \\
\text { Blinded assessment of primary outcome: DONE } \\
\text { Baseline measurement: NOT CLEAR. } \\
\text { Reliable primary outcome measure: NOT CLEAR. } \\
\text { Protection against contamination: NOT DONE } \\
\text { Intention-to-treat analysis. } \\
\text { Power calculation: DONE }\end{array}$ \\
\hline Participants & $\begin{array}{l}\text { Providers - GPs from two urban practices (total patient pop 10420). } \\
\text { Participating patients - patients using the telephone to request same-day appointments for themselves or } \\
\text { their children. } \\
\text { Country - UK }\end{array}$ \\
\hline Interventions & $\begin{array}{l}\text { I) Telephone consultation by a GP, followed by face-to-face appointment if appropriate ( } \mathrm{n}=194 \text { calls). } \\
\text { C) Normal face-to-face appointment with a GP ( } \mathrm{n}=194 \mathrm{calls} \text { ). } \\
\text { Exclusions: patients specifically asking to speak to the } \mathrm{dr} \text { by telephone for advice, those deemed urgent } \\
\text { cases, and those with no telephone number }\end{array}$ \\
\hline Outcomes & $\begin{array}{l}\text { GPs time (e.g. length of phone call vs length of face-to-face appointment) } \\
\text { Investigations and services. } \\
\text { Frequency of BP measurement, antibiotic prescriptions and number of problems considered at consulta- } \\
\text { tion. } \\
\text { Patient perceptions. }\end{array}$ \\
\hline
\end{tabular}


McKinstry 2002 (Continued)

\begin{tabular}{l|l|l}
\hline Notes & $\begin{array}{l}\text { Follow up: } 2 \text { weeks after consultation. } \\
\text { Trial lasted for 4 weeks. }\end{array}$ \\
\hline Risk of bias & Authors' judgement & Description \\
\hline Item & Yes & A - Adequate \\
\hline Allocation concealment? &
\end{tabular}

Richards 2002

\begin{tabular}{ll} 
ITS. \\
Clearly defined point when intervention occured: DONE \\
Intervention independent of other changes: DONE (all other systems kept constant until end of project) \\
$*$. \\
Sufficient data points before and after the intervention: DONE (3 before intervention and 9 after). \\
Formal test for trend: DONE (multivariate time series analysis). \\
Intervention unlikely to affect data collection: DONE (data collection sources same before \& after inter- \\
vention). \\
Blinded assessment of primary outcome(s): \\
DONE (objective outcomes). \\
Completeness of data set: DONE. \\
Reliable primary outcome measure(s): DONE (data checked against electronic records). \\
Power calculation: NOT CLEAR \\
\hline
\end{tabular}

Participants $\quad$ Providers - experienced practice nurses, who received 30 hrs of minor illness management training, in a large general practice. Three sites were involved with a study population of 20800

Participating patients - patients requesting same day appointment.

Country - UK

Interventions $\quad$ I) Nurse telephone consultation; with computerised management protocols developed by the practice ( $\mathrm{n}=$ 3452 calls).

c) Standard management: patients seen by GP ( $\mathrm{n}=1233$ calls).

\begin{tabular}{l|l}
\hline Outcomes & $\begin{array}{l}\text { Length of consultation } \\
\text { Use of services after contact } \\
\text { Costs }\end{array}$ \\
\hline Notes & $\begin{array}{l}\text { Sequential inclusion of the three sites into the study. } \\
\text { Data collected for one week each month over } 9 \text { months. } \\
\text { Total of } 4685 \text { patients. }\end{array}$ \\
\hline
\end{tabular}

Risk of bias

\begin{tabular}{lll}
\hline Item & Authors' judgement & Description \\
\hline Allocation concealment? & Unclear & D - Not used \\
\hline
\end{tabular}

Telephone consultation and triage: effects on health care use and patient satisfaction (Review) 
Stirewalt 1982

\begin{tabular}{|c|c|c|}
\hline Methods & \multicolumn{2}{|c|}{$\begin{array}{l}\text { RCT. } \\
\text { Concealment: NOT CLEAR (sealed envelope) } \\
\text { Follow up: DONE ( } 91 \% \text { for no of visits, } 82 \% \text { for pt satisfaction) } \\
\text { Blinded assessment of primary outcome(s): DONE (number of visits), NOT CLEAR (satisfaction) } \\
\text { Baseline measurement: DONE } \\
\text { Reliable primary outcome measure(s): DONE } \\
\text { Protection against contamination: NOT DONE } \\
\text { Power calculation: NOT CLEAR }\end{array}$} \\
\hline Participants & \multicolumn{2}{|c|}{$\begin{array}{l}\text { Providers - clerk in medical centre. } \\
\text { Participating patients - male patients visiting clinic without an appointment. } \\
\text { Country - USA }\end{array}$} \\
\hline Interventions & \multicolumn{2}{|c|}{$\begin{array}{l}\text { I) Telephone consultation by a clinic clerk using protocols for telephone triage ( } \mathrm{n}=279 \text { patients) } \\
\text { C) Usual care (i.e. given an appointment with } \mathrm{dr})(\mathrm{n}=282 \text { patients })\end{array}$} \\
\hline Outcomes & \multicolumn{2}{|c|}{$\begin{array}{l}\text { Scheduled and unscheduled visits to medical centre. } \\
\text { Hospitalisations. } \\
\text { Patient satisfaction }\end{array}$} \\
\hline Notes & \multicolumn{2}{|l|}{ Follow up: 12 months. } \\
\hline \multicolumn{3}{|l|}{ Risk of bias } \\
\hline Item & Authors' judgement & Description \\
\hline Allocation concealment? & Unclear & B - Unclear \\
\hline
\end{tabular}

Strasser 1979

$\begin{array}{ll}\text { Methods } & \text { CCT. } \\ \text { Concealment: NOT DONE (allocated to treatment and control groups in alternate weeks) } \\ \text { Follow up: DONE } \\ \text { Blinded assessment of primary outcome: DONE } \\ \text { Baseline measurement: NOT DONE } \\ \text { Reliable primary outcome measure(s): NOT CLEAR } \\ \text { Protection against contamination: NOT DONE } \\ \text { Power calculation: NOT DONE }\end{array}$


Strasser 1979 (Continued)

\begin{tabular}{|c|c|c|}
\hline Notes & \multicolumn{2}{|c|}{$\begin{array}{l}\text { Trial was also repeated in two other sites (a health } \\
\text { maintenance organization and in a primary care clinic) but little data from these are presented. } \\
\text { Trial } 29 \text { weeks long (September 1976-April 1977). } \\
\text { Follow up: } 2 \text { days }\end{array}$} \\
\hline \multicolumn{3}{|l|}{ Risk of bias } \\
\hline Item & Authors' judgement & Description \\
\hline Allocation concealment? & No & $\mathrm{C}$ - Inadequate \\
\hline
\end{tabular}

Thompson 1999

\begin{tabular}{|c|c|c|}
\hline Methods & \multicolumn{2}{|c|}{$\begin{array}{l}\text { RCT } \\
\text { Concealment: DONE (same as Lattimer study) } \\
\text { Follow up: DONE ( } 94 \% \text { follow up) } \\
\text { Blinded assessment of primary outcomes: DONE } \\
\text { Reliable primary outcome measure: NOT CLEAR } \\
\text { Power calculation: NOT DONE }\end{array}$} \\
\hline Participants & \multicolumn{2}{|c|}{$\begin{array}{l}\text { Providers- nurses with } 6 \text { weeks training before trial started. Based in GP co-operative of } 55 \text { GP's covering } \\
\text { out-of-hours care between } 11.15 \mathrm{pm} \text { and } 8 \mathrm{am} \text {. } \\
\text { Participating patients- GP practice population of } 97,000 \\
\text { Country- UK }\end{array}$} \\
\hline Interventions & \multicolumn{2}{|c|}{$\begin{array}{l}\text { I) Nurse telephone consultation using computer assisted algorithms. ( } \mathrm{n}=100 \text { calls). } \\
\text { C) Standard practice: telephone consultation by deputising service doctor ( } \mathrm{n}=123 \text { calls) }\end{array}$} \\
\hline Outcomes & \multicolumn{2}{|c|}{$\begin{array}{l}\text { Mortality, visits to A\& E dept and surgery, home visits, unplanned hospitalisations, } \\
\text { calls handled by telephone advice alone. }\end{array}$} \\
\hline Notes & \multicolumn{2}{|c|}{$\begin{array}{l}\text { Study was an adjunct to Lattimer trial. } \\
\text { Study conducted in } 1997 . \\
\text { Follow up: mortality } 7 \text { days, visits to A\&E, GP, hospitalisations at } 3 \text { and } 7 \text { days }\end{array}$} \\
\hline \multicolumn{3}{|l|}{ Risk of bias } \\
\hline Item & Authors' judgement & Description \\
\hline Allocation concealment? & Yes & A - Adequate \\
\hline
\end{tabular}


Vedsted 2001

\begin{tabular}{|c|c|c|}
\hline Methods & \multicolumn{2}{|c|}{$\begin{array}{l}\text { ITS } \\
1988-1997 \\
\text { Intervention independent of other changes: NOT DONE. } \\
\text { Sufficient data points: DONE ( } 4 \text { before and } 5 \text { after). } \\
\text { Formal test for trend: DONE. } \\
\text { Intervention unlikely to affect data collection: NOT DONE (change from manual to automatic after } \\
\text { intervention). } \\
\text { Blinded assessment of primary outcome: DONE } \\
\text { Completeness of data set - DONE (all contacts registered on central database) } \\
\text { Reliable primary outcome measure - before intervention - NOT CLEAR, after intervention - DONE }\end{array}$} \\
\hline Participants & \multicolumn{2}{|c|}{$\begin{array}{l}\text { Providers - GPs (all calls to out of hours service go through centralised telephone triage by a GP). } \\
\text { Participating patients - inhabitants of the county of Aarhus requiring out of hours care from their GP. } \\
\text { County has } 630000 \text { inhabitants. } \\
\text { Country - Denmark }\end{array}$} \\
\hline Interventions & \multicolumn{2}{|c|}{ I) Telephone consultation offering advice, a surgery consultation or a home visit } \\
\hline Outcomes & \multicolumn{2}{|l|}{ Contacts with $A \& E$. } \\
\hline Notes & \multicolumn{2}{|c|}{4 yrs before data and 5 years after. } \\
\hline \multicolumn{3}{|l|}{ Risk of bias } \\
\hline Item & Authors' judgement & Description \\
\hline Allocation concealment? & Unclear & D - Not used \\
\hline
\end{tabular}

$\mathrm{RCT}=$ randomised controlled trial

ITS = Interrupted time series

$\mathrm{CBA}=$ controlled before after study

$\mathrm{GP}=$ general practitioner

ER - emergency room

A\&E - accident and emergency department

* - additional information obtained from author

\section{Characteristics of excluded studies [ordered by study ID]}

\begin{tabular}{l|l}
\hline Study & Reason for exclusion \\
\hline Christensen 1998 & Uncontrolled before/after study. \\
\hline Cragg 1997 & $\begin{array}{l}\text { Study compares GP deputising service with patients own GP. Although this includes some telephone consultation } \\
\text { we did not feel that this was a designated telephone consultation service }\end{array}$
\end{tabular}


(Continued)

\begin{tabular}{|c|c|}
\hline Dale 2003 & $\begin{array}{l}\text { RCT of telephone triage for callers who present with non serious problems. Study is excluded because no data } \\
\text { on outcomes is given for control group. Instead data is presented on intervention group only (separated into } \\
\text { those triaged as requiring an ambulance and those not requiring an ambulance) }\end{array}$ \\
\hline de Groot 2002 & Uncontrolled before/after study. \\
\hline Elwyn 1999 & Uncontrolled before/after study. \\
\hline Franco 1997 & Historical control used. \\
\hline Gallagher 1998 & Uncontrolled before/after study. \\
\hline Jones 2001 & Uncontrolled before/after study. \\
\hline Lee 2002 & $\begin{array}{l}\text { Authors only provide data on whether parents complied with the advice they were given. Objective data on } \\
\text { service use in both groups is not provided }\end{array}$ \\
\hline Munro 2000 & Uncontrolled before/after study \\
\hline O’Connell 2001 & Uncontrolled before/after study \\
\hline Richards 2004 & One type of nurse telephone consultation (NHS direct) vs another (practice nurse) \\
\hline Salk 1998 & $\begin{array}{l}\text { Study compares the agreement between telephone triage and face to face triage and do not look at any other } \\
\text { outcomes }\end{array}$ \\
\hline SWOOP 1997 & Uncontrolled study. \\
\hline Vedsted 1999 & Insufficient data points reported to meet inclusion criteria for ITS \\
\hline
\end{tabular}

Characteristics of ongoing studies [ordered by study ID]

\section{Richards}

\begin{tabular}{ll}
\hline Trial name or title & NHS Direct versus practice based nurse telephone triage: a randomised controlled trial \\
\hline Methods & Patients requesting same day GP appointments between 8.30 and 5.00pm Monday to Friday \\
\hline Participants & Practice based triage by a nurse or triage by a NHS Direct Nurse \\
\hline Interventions & $\begin{array}{l}\text { Length of consultation } \\
\text { Accident and Emergency use } \\
\text { Cost }\end{array}$
\end{tabular}




\section{Richards (Continued)}

\begin{tabular}{ll}
\hline Starting date & July 2001 \\
\hline Contact information & $\begin{array}{l}\text { Professor David Richards } \\
\text { School of Nursing, Midwifery and Health Visiting } \\
\text { Coupland III } \\
\text { University of Manchester } \\
\text { Oxford Road } \\
\text { Manchester } \\
\text { M13 9PL }\end{array}$ \\
\hline Notes & \\
\hline
\end{tabular}

\section{Vorster}

Trial name or title Practice based nurse telephone triage for same day patient requests

\begin{tabular}{ll}
\hline Methods & \\
\hline Participants & Patients requesting same day GP appointments. \\
\hline Interventions & $\begin{array}{l}\text { Nurse telephone triage compared with usual receptionist handling of patients requesting a same day appoin- } \\
\text { ment }\end{array}$ \\
\hline Outcomes & Number, length and cost of appointments. \\
\hline Starting date & $\begin{array}{l}\text { Dr Mark Vorster } \\
\text { Hitchin } \\
\text { Hertfordshire } \\
\text { UK }\end{array}$ \\
\hline Notes & \\
\hline
\end{tabular}


DATA ANDANALYSES

Comparison 1. Telephone consultation versus standard management (no telephone consultation)

\begin{tabular}{|c|c|c|c|c|}
\hline Outcome or subgroup title & $\begin{array}{l}\text { No. of } \\
\text { studies }\end{array}$ & $\begin{array}{c}\text { No. of } \\
\text { participants }\end{array}$ & Statistical method & Effect size \\
\hline $\begin{array}{l}1 \text { General Practitioner } \\
\text { appointments at surgery }\end{array}$ & & & Other data & No numeric data \\
\hline $\begin{array}{l}2 \text { Calls handled by telephone } \\
\text { advice alone }\end{array}$ & & & Other data & No numeric data \\
\hline 3 Visits to A\&E departments & & & Other data & No numeric data \\
\hline 4 Hospital admissions & & & Other data & No numeric data \\
\hline $\begin{array}{l}5 \text { Home visits by doctor } \\
\text { (in-surgery hours) }\end{array}$ & & & Other data & No numeric data \\
\hline 6 Out of hours contacts & & & Other data & No numeric data \\
\hline 7 Patient satisfaction & & & Other data & No numeric data \\
\hline 8 Cost & & & Other data & No numeric data \\
\hline
\end{tabular}

Comparison 2. Telephone consultation by one type of health care worker versus another

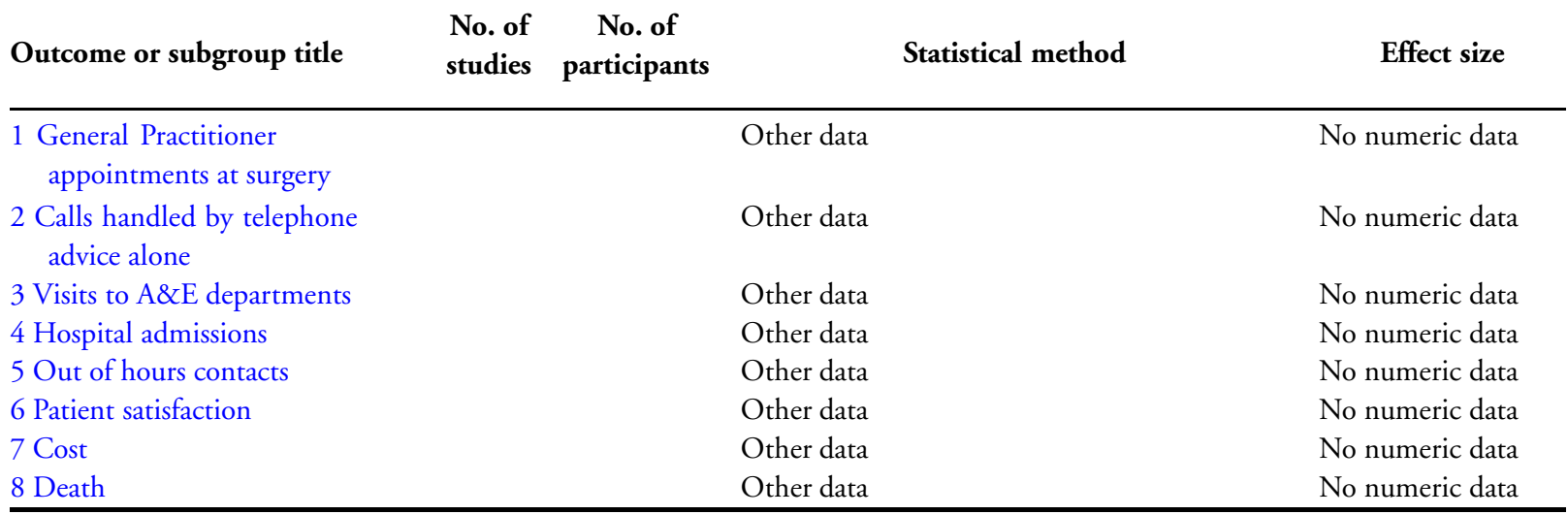

\section{Analysis I.I. Comparison I Telephone consultation versus standard management (no telephone consultation), Outcome I General Practitioner appointments at surgery.}

General Practitioner appointments at surgery

\begin{tabular}{|c|c|c|c|}
\hline Study & Comparison & Results & Notes \\
\hline Jiwa 2002 & $\begin{array}{l}\text { ITS } \\
\text { Telephone consultation by GP }\end{array}$ & $\begin{array}{l}\text { Average number of visits during trial } \\
\text { period. } \\
\text { Change in level } 39.3 \% \text { reduction } \\
(95 \% \text { CI } 29-51 \%) \\
\mathrm{P}=<0.001\end{array}$ & Significant reduction in visits. \\
\hline
\end{tabular}

Telephone consultation and triage: effects on health care use and patient satisfaction (Review)

Copyright @ 2009 The Cochrane Collaboration. Published by John Wiley \& Sons, Ltd. 


\begin{tabular}{|c|c|c|c|}
\hline McKinstry 2002 & $\begin{array}{l}\text { RCT } \\
\text { Telephone consultation by GP ver- } \\
\text { sus face to face appointment with } \\
\text { GP }\end{array}$ & $\begin{array}{l}\text { Visits in two week follow up period. } \\
\text { TT mean }=0.6(\mathrm{SD} 0.8) \\
\text { Face mean }=0.4(\mathrm{SD} 0.7) \\
\text { Mean difference }=0.2(95 \% \text { CI } 0.0 \\
\text { to } 0.3) \mathrm{p}=0.01\end{array}$ & $\begin{array}{l}\text { Significant increase in visits to GP in } \\
\text { telephone consultation group }\end{array}$ \\
\hline Richards 2002 & $\begin{array}{l}\text { ITS } \\
\text { Telephone consultation by nurse }\end{array}$ & $\begin{array}{l}\text { Patients having immediate GP ap- } \\
\text { pointment } \\
\text { Intervention } 1407 / 3452 \\
\text { Control } 789 / 1233 \\
\text { RD }-0.23(95 \% \text { CI }-0.26 \text { to }-0.20) \\
\text { Number of return consultations } \\
\text { within one month } \\
\text { TT mean }=1.24(\mathrm{SD} 1.78) \\
\text { Face mean }=0.93(1.30) \\
\text { Mean difference }=0.32(95 \% \text { CI } 0 . \\
22 \text { to } 0.41) \mathrm{p}=<0.001\end{array}$ & $\begin{array}{l}\text { Significant reduction in immediate } \\
\text { GP visits but then significant in- } \\
\text { crease in return visits (within one } \\
\text { month) in the telephone consulta- } \\
\text { tion group }\end{array}$ \\
\hline
\end{tabular}

\section{Analysis I.2. Comparison I Telephone consultation versus standard management (no telephone consultation), Outcome 2 Calls handled by telephone advice alone.}

Calls handled by telephone advice alone

\begin{tabular}{|c|c|c|c|}
\hline Study & Comparison & Results & Notes \\
\hline Jiwa 2002 & $\begin{array}{l}\text { ITS } \\
\text { Telephone consultation by GP }\end{array}$ & $\begin{array}{l}180(29.3 \%) \text { of calls were handled } \\
\text { by telephone advice alone and a fur- } \\
\text { ther } 138(22.4 \%) \text { were offered a pre- } \\
\text { scription without face-to-face con- } \\
\text { sultation }\end{array}$ & \\
\hline McKinstry 2002 & $\begin{array}{l}\text { RCT } \\
\text { Telephone consultation by GP ver- } \\
\text { sus face to face appointment with } \\
\text { GP }\end{array}$ & $\begin{array}{l}72.2 \% \text { of calls were handled by tele- } \\
\text { phone advice alone. }\end{array}$ & \\
\hline Richards 2002 & $\begin{array}{l}\text { ITS } \\
\text { Telephone consultation by nurse }\end{array}$ & $\begin{array}{l}25.5 \% \text { of calls in the nurse consul- } \\
\text { tation group were managed by tele- } \\
\text { phone advice alone }\end{array}$ & \\
\hline
\end{tabular}

\section{Analysis I.3. Comparison I Telephone consultation versus standard management (no telephone} consultation), Outcome 3 Visits to A\&E departments.

Visits to A\&E departments

\begin{tabular}{llll}
\hline Study & Comparison & Results & Notes
\end{tabular}


Visits to A\&E departments (Continued)

\begin{tabular}{|c|c|c|c|}
\hline Darnell 1985 & $\begin{array}{l}\text { RCT } \\
\text { Out-of-hours telephone access to dr } \\
\text { (Group } 1 \text { without patients notes, } \\
\text { Group } 2 \text { with patient notes), versus } \\
\text { no telephone access to dr after hours }\end{array}$ & $\begin{array}{l}\text { Patients with visits to ER } \\
\text { Intervention: } \\
\text { Baseline 690/1849, Year } 1 \text { 592/ } \\
\text { 1849, Year } 2584 / 1618 \\
\text { Control: Baseline } 310 / 778 \text {, year } 1 \\
\text { 265/778, year } 2 \text { 264/691 } \\
\text { Adjusted risk difference } \\
\text { Year } 1=-0.04 \\
\text { Year } 2=-0.04\end{array}$ & $\begin{array}{l}\text { Slight decrease in intervention } \\
\text { group. }\end{array}$ \\
\hline McKinstry 2002 & $\begin{array}{l}\text { RCT } \\
\text { Telephone consultation by GP ver- } \\
\text { sus face to face appointment with } \\
\text { GP }\end{array}$ & $\begin{array}{l}\text { Number of visits to A\&E in } 2 \text { week } \\
\text { period following call. } \\
\text { TT mean }=0(\text { SD 0.2) } \\
\text { Face mean }=0(\text { SD 0.1) } \\
\text { Difference }=0(95 \% \text { CI }-0.1,0.0)\end{array}$ & $\begin{array}{l}\text { No significant difference between } \\
\text { two groups. }\end{array}$ \\
\hline Richards 2002 & $\begin{array}{l}\text { ITS } \\
\text { Telephone consultation by nurse. }\end{array}$ & $\begin{array}{l}\text { Number of visits to A \& E de- } \\
\text { partments within } 1 \text { month of initial } \\
\text { call: mean pre }=0.010 \text { (SD } 0.10) \text {, } \\
\text { mean post } 0.033(0.19) \text {, difference } \\
\text { in means } 0.023(95 \% \text { CI } 0.015 \text { to } 0 \text {. } \\
032), p=0.001 \\
\text { difference in level } 0.023 \text { ( } 95 \% \text { CI } 0 \text {. } \\
015 \text { to } 0.032 \text { ). }\end{array}$ & $\begin{array}{l}\text { Significant increase in number of } \\
\text { visits to } A \& E \text {. }\end{array}$ \\
\hline Vedsted 2001 & $\begin{array}{l}\text { ITS } \\
\text { Telephone consultation by GP (out- } \\
\text { of-hours) }\end{array}$ & $\begin{array}{l}\text { Mean change in level pre to post was } \\
+0.011(\mathrm{SE}=0.004, \mathrm{p}=0.039) \\
\text { Change in slope pre to post was }+0 \text {. } \\
002 \text { (SE } 0.001 ; \mathrm{p}=0.14)\end{array}$ & $\begin{array}{l}\text { Authors did not look for serial cor- } \\
\text { relation and the analysis was redone } \\
\text { using time series regression tech- } \\
\text { niques }\end{array}$ \\
\hline
\end{tabular}

\section{Analysis I.4. Comparison I Telephone consultation versus standard management (no telephone} consultation), Outcome 4 Hospital admissions.

\section{Hospital admissions}

\begin{tabular}{|c|c|c|c|}
\hline Study & Comparison & Results & Notes \\
\hline Darnell 1985 & $\begin{array}{l}\text { RCT } \\
\text { After hours telephone access to dr } \\
\text { (Group } 1 \text { without patients notes, } \\
\text { Group } 2 \text { with patient notes), versus } \\
\text { no telephone access to dr after hours }\end{array}$ & $\begin{array}{l}\text { Patients with hospital admissions. } \\
\text { Intervention: } \\
\text { baseline 461/1849, year } 1382 / 1849 \text {, } \\
\text { year } 2 \text { 392/1618 } \\
\text { Control: } \\
\text { baseline } 183 / 778 \text {, year } 1 \text { 197/778, } \\
\text { year 2, 177/691 } \\
\text { Adjusted risk difference: } \\
\text { Year 1: } 0.06 \\
\text { Year 2: } 0.028\end{array}$ & \\
\hline
\end{tabular}


Stirewalt 1982

Specialised telephone service run by clinic clerk or usual care (appointment with dr)
Mean adjusted risk difference in hos-

pitalizations.

Significant reduction in hospitalisations at 12 months.

At 6 months: 0.06

At 12 months: $0.17(\mathrm{p}=<0.05)$

Analysis I.5. Comparison I Telephone consultation versus standard management (no telephone consultation), Outcome 5 Home visits by doctor (in-surgery hours).

Home visits by doctor (in-surgery hours)

\begin{tabular}{ll|l|l}
\hline Study & Comparison & Results & Notes \\
\hline Richards 2002 & $\begin{array}{l}\text { ITS } \\
\text { Telephone consulation by nurse. }\end{array}$ & $\begin{array}{l}\text { Number of patients receiving a home } \\
\text { visit }\end{array}$ & Non significant reduction \\
& & $\begin{array}{l}\text { Int }=418 / 3452 \\
\text { Control }=176 / 1233 \\
\mathrm{RD}=-0.02(-0.04 \text { to } 0.00)\end{array}$ \\
\hline
\end{tabular}

Analysis I.6. Comparison I Telephone consultation versus standard management (no telephone consultation), Outcome 6 Out of hours contacts.

Out of hours contacts

\begin{tabular}{|c|c|c|c|}
\hline Study & Comparison & Results & Notes \\
\hline McKinstry 2002 & $\begin{array}{l}\text { RCT } \\
\text { Telephone consultation by GP ver- } \\
\text { sus face to face appointment with } \\
\text { GP }\end{array}$ & $\begin{array}{l}\text { Number of out-of-hours contacts } \\
\text { TT mean }=0.0(\text { SD 0.2) } \\
\text { Face mean }=0(\text { SD 0.1) } \\
\text { Difference }=0\end{array}$ & $\begin{array}{l}\text { No difference in out of hours con- } \\
\text { tacts. }\end{array}$ \\
\hline Richards 2002 & $\begin{array}{l}\text { ITS } \\
\text { Telephone consulation by nurse. }\end{array}$ & $\begin{array}{l}\text { Number of out of hours contacts } \\
\text { Mean }(\mathrm{SD}) \text { : } \\
\text { Int }=0.11(0.49) \\
\text { Control }=0.08(0.38) \\
\text { Mean difference } 0.04(95 \% \text { CI } 0.01 \\
\text { to } 0.07) \mathrm{p}=0.005\end{array}$ & $\begin{array}{l}\text { Small but signficant increase in out } \\
\text { of hours contacts in intervention } \\
\text { group }\end{array}$ \\
\hline
\end{tabular}

Analysis I.7. Comparison I Telephone consultation versus standard management (no telephone consultation), Outcome 7 Patient satisfaction.

Patient satisfaction

\begin{tabular}{llll}
\hline Study & Comparison & Results & Notes \\
\hline Darnell 1985 & $\begin{array}{l}\text { RCT } \\
\text { Out-of-hours telephone access to dr } \\
\text { (Group 1 without patients notes, }\end{array}$ & $\begin{array}{l}78 \% \text { of those interviewed were satis- } \\
\text { fied with length of time before phys- } \\
\text { cian responded, length of consulta- }\end{array}$ & $\begin{array}{l}\text { Interviews with subset of } 241 \text { of pa- } \\
\text { tients in the intervention group }\end{array}$ \\
\hline
\end{tabular}

Telephone consultation and triage: effects on health care use and patient satisfaction (Review)

Copyright @ 2009 The Cochrane Collaboration. Published by John Wiley \& Sons, Ltd. 
Patient satisfaction (Continued)

Group 2 with patient notes), versus tion and care provided

no telephone access to $\mathrm{dr}$ after hours

\begin{tabular}{|c|c|c|c|}
\hline Jiwa 2002 & $\begin{array}{l}\text { ITS } \\
\text { Telephone consultation by GP }\end{array}$ & $\begin{array}{l}98 \% \text { satisfied or very satisfied with } \\
\text { outcome of the telephone consulta- } \\
\text { tion and } 84 \% \text { said they would be } \\
\text { happy to receive service again in the } \\
\text { future }(95 \% \text { CI } 76,90 \%)\end{array}$ & $74 \%$ response rate. \\
\hline McKinstry 2002 & $\begin{array}{l}\text { RCT } \\
\text { Telephone consultation by GP ver- } \\
\text { sus face to face appointment with } \\
\text { GP }\end{array}$ & $\begin{array}{l}\text { Pt's prepared to use telephone con- } \\
\text { sultation in future } \\
\text { TT }=59 \% \\
\text { Face }=50.6 \% \\
\text { Difference }=-8.4 \%(-23.1 \% \text { to } 6 . \\
4 \%) \\
\text { There was no difference in how well } \\
\text { patients thought problem was un- } \\
\text { derstood and how well treatment for } \\
\text { their problem was explained to them }\end{array}$ & Less than $50 \%$ response rate. \\
\hline Stirewalt 1982 & $\begin{array}{l}\text { RCT } \\
\text { Specialised telephone service run by } \\
\text { clinic clerks versus standard clinic } \\
\text { care }\end{array}$ & $\begin{array}{l}\text { Used two satisfaction with care } \\
\text { scales. On both scales patients in in- } \\
\text { tervention group were more satisfied } \\
\text { and this was significant at the overall } \\
\text { multivariate level }\end{array}$ & $82 \%$ follow up. \\
\hline
\end{tabular}

Analysis I.8. Comparison I Telephone consultation versus standard management (no telephone consultation), Outcome 8 Cost.

\section{Cost}

\begin{tabular}{llll}
\hline Study & Comparison & Results & Notes \\
\hline Jiwa 2002 & $\begin{array}{l}\text { ITS } \\
\text { Telephone consultation by GP }\end{array}$ & $\begin{array}{l}\text { Telephone bills increased by } 2200 \text { per } \\
\text { quarter over study period }\end{array}$ & Telephone bill increased by 26\% \\
\hline Richards 2002 & $\begin{array}{l}\text { ITS } \\
\text { Telephone consultation by nurse. }\end{array}$ & $\begin{array}{l}\text { Cost before 21.89 (SD 23.89) } \\
\text { Cost after 23.37 (SD 30.05) } \\
\text { Mean difference 1.48 (95\% CI -0.19 } \\
\text { to 3.15) p=0.081 }\end{array}$ & $\begin{array}{l}\text { Cost based on day plus total costs in- } \\
\text { curred one month after request for } \\
\text { sampointment }\end{array}$ \\
\hline
\end{tabular}




\section{Analysis 2.1. Comparison 2 Telephone consultation by one type of health care worker versus another, Outcome I General Practitioner appointments at surgery.}

General Practitioner appointments at surgery

\begin{tabular}{|c|c|c|c|}
\hline Study & Comparison & Results & Notes \\
\hline Lattimer 1998 & $\begin{array}{l}\text { RCT } \\
\text { Nurse telephone consultation for } \\
\text { out-of hours care versus standard } \\
\text { out-of-hours care from GP deputis- } \\
\text { ing service }\end{array}$ & $\begin{array}{l}\text { Number of patients visiting GP } \\
\text { (number of calls is denominator) } \\
\text { during the trial period. } \\
\text { Control = } 1934(26 \%) \\
\text { Intervention }=1177(16 \%) \\
\text { Reduction in visits to GP }=\text { RD }-0 . \\
10(95 \% \text { CI }-0.11 \text { to }-0.09)\end{array}$ & Significant reduction \\
\hline Thompson 1999 & $\begin{array}{l}\text { RCT } \\
\text { Nurse telephone consultation for } \\
\text { out-of-hours care versus GP deputis- } \\
\text { ing service for out-of-hours care be- } \\
\text { tween } 11.15 \mathrm{pm} \text { and } 8 \mathrm{am}\end{array}$ & $\begin{array}{l}\text { Attended daytime surgery within } 3 \\
\text { days. } \\
\text { Int }=8 / 100 \text {, control }=18 / 123 \\
\text { RD }-0.07 \text { ( } 95 \% \text { CI }-0.15 \text { to } 0.02)\end{array}$ & $\begin{array}{l}\text { Trend towards less visits in interven- } \\
\text { tion group but not significant }\end{array}$ \\
\hline
\end{tabular}

\section{Analysis 2.2. Comparison 2 Telephone consultation by one type of health care worker versus another,} Outcome 2 Calls handled by telephone advice alone.

Calls handled by telephone advice alone

\begin{tabular}{l|l|l|l}
\hline Study & Comparison & Results & Notes \\
\hline Lattimer 1998 & $\begin{array}{l}\text { RCT } \\
\text { Nurse telephone consultation for } \\
\text { out-of hours care versus standard } \\
\text { out-of-hours care from GP deputis- } \\
\text { ing service }\end{array}$ & $\begin{array}{l}\text { Nurses in the intervention group } \\
\text { and doctors in the control group } \\
\text { managed 50\% of calls by telephone } \\
\text { advice alone }\end{array}$ \\
\hline Thompson 1999 & $\begin{array}{l}\text { Nurse telephone consultation for } \\
\text { out-of-hours care versus GP deputis- } \\
\text { ing service for out-of-hours care be- } \\
\text { tween 11.15pm and 8am }\end{array}$ & $\begin{array}{l}59 \% \text { of calls in the nurse triage group } \\
\text { and } 62 \% \text { of calls in the control group } \\
\text { were managed by telephone advice } \\
\text { alone }\end{array}$ \\
\hline
\end{tabular}

Analysis 2.3. Comparison 2 Telephone consultation by one type of health care worker versus another, Outcome 3 Visits to A\&E departments.

Visits to A\&E departments

\begin{tabular}{|c|c|c|c|}
\hline Study & Comparison & Results & Notes \\
\hline Lattimer 1998 & $\begin{array}{l}\text { RCT } \\
\text { Nurse telephone consultation for } \\
\text { out-of hours care versus standard } \\
\text { out-of-hours care from GP deputis- }\end{array}$ & $\begin{array}{l}\text { Number of attendances at } A \& E \\
\text { within } 3 \text { days of call. Figures are } \\
\text { numbers ( } \% \text { of calls). }\end{array}$ & $\begin{array}{l}\text { Slightly higher in intervention } \\
\text { group but they calculate that based } \\
\text { on data, at worst, } 8 \text { additional atten- }\end{array}$ \\
\hline
\end{tabular}

Telephone consultation and triage: effects on health care use and patient satisfaction (Review)

Copyright @ 2009 The Cochrane Collaboration. Published by John Wiley \& Sons, Ltd. 
Visits to A\&E departments (Continued)

ing service
Int $=412(5.7 \%)$

Control 398 (5.4\%)

RD 0.00 (95\% CI 0.00 to 0.01$)$ dance's per year could be expected

Visits to ER within $48 \mathrm{hrs}$ of call.

Int $=37 / 161(23 \%)$

slight increase in visits in intervention group but is not significant

Control $=38 / 177(21 \%)$

RD 0.02 (95\% CI -0.07 to 0.10$)$

Number of attendances at A\&E Non significant trend towards more within 3 days of call.

Int $=3$, control $=2$

RD 0.01 (95\% CI -0.03 to 0.05$)$ visits in intervention group but numbers are small and confidence intervals wide

Analysis 2.4. Comparison 2 Telephone consultation by one type of health care worker versus another, Outcome 4 Hospital admissions.

\section{Hospital admissions}

\begin{tabular}{|c|c|c|c|}
\hline Study & Comparison & Results & Notes \\
\hline Lattimer 1998 & $\begin{array}{l}\text { RCT } \\
\text { Nurse telephone consultation for } \\
\text { out-of hours care versus standard } \\
\text { out-of-hours care from GP deputis- } \\
\text { ing service }\end{array}$ & $\begin{array}{l}\text { Number of emergency hospital ad- } \\
\text { missions during trial period of pa- } \\
\text { tients who had been in contact with } \\
\text { out of hours service within } \\
24 \text { hrs: } \\
\text { Int = } 375(5.2 \%) \text {, Control = } 440(6 \text {. } \\
0 \%) \\
\text { RD }-0.01(95 \% \text { CI }-0.02 \text { to } 0.00) \\
3 \text { days: } \\
\text { Int }=428(6.0 \%) \text {, Control = } 507(6 \text {. } \\
9 \%) \\
\text { RD }-0.01(95 \% \text { CI }-0.02 \text { to } 0.00)\end{array}$ & No significant difference \\
\hline Thompson 1999 & $\begin{array}{l}\text { RCT } \\
\text { Nurse telephone consultation for } \\
\text { out-of-hours care versus GP deputis- } \\
\text { ing service for out-of-hours care be- } \\
\text { tween } 11.15 \mathrm{pm} \text { and } 8 \mathrm{am}\end{array}$ & $\begin{array}{l}\text { Number of emergency hospital ad- } \\
\text { missions during trial period of pa- } \\
\text { tients who had been in contact with } \\
\text { out of hours service within } \\
24 \text { hrs: } \\
\text { Int }=2 \text {, control = } 8 \\
\text { RD }-0.05 \text { ( } 95 \% \text { CI }-0.10 \text { to } 0.01) \\
3 \text { days: } \\
\text { Int }=5 \text {, control = } 8 \\
\text { RD }-0.02(95 \% \text { CI }-0.08 \text { to } 0.05)\end{array}$ & $\begin{array}{l}\text { Trend towards less hospital admis- } \\
\text { sions in intervention group but the } \\
\text { numbers are small and result not sig- } \\
\text { nificant }\end{array}$ \\
\hline
\end{tabular}

Telephone consultation and triage: effects on health care use and patient satisfaction (Review) 
Analysis 2.5. Comparison 2 Telephone consultation by one type of health care worker versus another, Outcome 5 Out of hours contacts.

Out of hours contacts

\begin{tabular}{|c|c|c|c|}
\hline Study & Comparison & Results & Notes \\
\hline Lattimer 1998 & $\begin{array}{l}\text { RCT } \\
\text { Nurse telephone consultation for } \\
\text { out-of hours care versus standard } \\
\text { out-of-hours care from GP deputis- } \\
\text { ing service }\end{array}$ & $\begin{array}{l}\text { Numbers of patients receiving a } \\
\text { home visit by a GP during the trial } \\
\text { year. } \\
\text { Control }=1745(24 \%) \\
\text { Int }=1317(18 \%) \\
\text { RD }-0.06(-0.07 \text { to }-0.04)\end{array}$ & $\begin{array}{l}\text { Significant reduction in number of } \\
\text { home visits by deputising service in } \\
\text { intervention group }\end{array}$ \\
\hline Thompson 1999 & $\begin{array}{l}\text { RCT } \\
\text { Nurse telephone consultation for } \\
\text { out-of-hours care versus GP deputis- } \\
\text { ing service for out-of-hours care be- } \\
\text { tween } 11.15 \mathrm{pm} \text { and } 8 \mathrm{am}\end{array}$ & $\begin{array}{l}\text { Int }=21, \text { control }=41 \\
R D-0.12(-0.24 \text { to }-0.11)\end{array}$ & $\begin{array}{l}\text { Significant reduction in number of } \\
\text { home visits by deputising service in } \\
\text { intervention group }\end{array}$ \\
\hline
\end{tabular}

Analysis 2.6. Comparison 2 Telephone consultation by one type of health care worker versus another, Outcome 6 Patient satisfaction.

Patient satisfaction

\begin{tabular}{ll|l|l}
\hline Study & Comparison & Results & Notes \\
\hline Strasser 1979 & $\begin{array}{l}\text { CCT } \\
\text { Telephone consultation by health as- } \\
\text { sistant versus telephone advice from a } \\
\text { doctor or a nurse }\end{array}$ & $\begin{array}{l}\text { Detailed information on satisfaction } \\
\text { not given but authors say that in re- } \\
\text { sponse to } 9 \text { out of } 10 \text { questions asked } \\
\text { slightly higher satisfaction was regis- } \\
\text { tered in the treatment group }\end{array}$ & Response rate not given \\
\hline
\end{tabular}

Analysis 2.7. Comparison 2 Telephone consultation by one type of health care worker versus another, Outcome 7 Cost.

\section{Cost}

\begin{tabular}{|c|c|c|c|}
\hline Study & Comparison & Results & Notes \\
\hline Lattimer 1998 & $\begin{array}{l}\text { RCT } \\
\text { RCT } \\
\text { Nurse telephone consultation for } \\
\text { out-of hours care versusstandard out- } \\
\text { of-hours care from GP deputising } \\
\text { service }\end{array}$ & $\begin{array}{l}\text { Cost of providing nurse telephone } \\
\text { consultation service was } £ 81237 \text { a } \\
\text { year. There was a } £ 94,422 \text { reduction } \\
\text { of other costs arising from reduced } \\
\text { emergency admissions. Also a reduc- } \\
\text { tion of GP costs of } £ 16928 \text { a year } \\
\text { through reduced travel costs and re- } \\
\text { duced surgery appointments }\end{array}$ & \\
\hline
\end{tabular}




\section{Analysis 2.8. Comparison 2 Telephone consultation by one type of health care worker versus another, Outcome 8 Death.}

Death

\begin{tabular}{|c|c|c|c|}
\hline Study & Comparison & Results & Notes \\
\hline Lattimer 1998 & $\begin{array}{l}\text { RCT } \\
\text { Nurse telephone consultation for } \\
\text { out-of hours care versus standard } \\
\text { out-of-hours care from GP deputis- } \\
\text { ing service }\end{array}$ & $\begin{array}{l}\text { Number of deaths during trial of pa- } \\
\text { tients who had been in contact with } \\
\text { out of hours service within previous } \\
7 \text { days. } \\
\text { Int }=58(0.57 \%) \\
\text { Control }=67(0.66 \%) \\
\text { RD } 0(95 \% \text { CI } 0.00 \text { to } 0.00)\end{array}$ & $\begin{array}{l}\text { No significant difference between } \\
\text { the two groups. }\end{array}$ \\
\hline Thompson 1999 & $\begin{array}{l}\text { RCT } \\
\text { Nurse telephone consultation for } \\
\text { out-of-hours care versus GP deputis- } \\
\text { ing service for out-of-hours care be- } \\
\text { tween } 11.15 \mathrm{pm} \text { and } 8 \mathrm{am}\end{array}$ & $\begin{array}{l}\text { Number of deaths during trial of pa- } \\
\text { tients who had been in contact with } \\
\text { out of hours service within previous } \\
7 \text { days. } \\
\text { Int }=2 \text {, control }=2 \text {, } \\
\text { RD } 0.00(95 \% \text { CI }-0.03 \text { to } 0.04)\end{array}$ & $\begin{array}{l}\text { No significant difference between } \\
\text { the two groups. }\end{array}$ \\
\hline
\end{tabular}

\section{ADDITIONAL TABLES}

Table 1. Search strategies for review update (2008)

\begin{tabular}{|c|c|}
\hline Database & Search strategy \\
\hline CINAHL & $\begin{array}{l}1 \text { Triage/ } \\
2 \text { (triage or helpline? or hotline?).tw. } \\
3 \text { Telephone Information Services/ } \\
4 \text { Family Practice/ } \\
5 \text { Emergency Medicine/ } \\
6 \text { or/1-5 } \\
7 \text { (telephone or phone).tw. } \\
86 \text { and } 7 \\
9 \text { ((telephone or phone) adj consultation?).tw. } \\
10 \text { ((telephone or phone) adj triage).tw. } \\
11 \text { NHS direct.tw. } \\
12 \text { or/8-11 } \\
13 \text { clinical trial/ } \\
14 \text { (controlled adj (study or trial)).tw. } \\
15 \text { random\$.tw. } \\
16 \text { (random } \$ \text { adj } 1 \text { (allocat } \$ \text { or assign\$)).tw. } \\
17 \text { comparative studies/ } \\
18 \text { experiment } \$ . t w . \\
19 \text { (time adj series).tw. } \\
20 \text { impact.tw. } \\
21 \text { intervention?.tw. }\end{array}$ \\
\hline
\end{tabular}


Table 1. Search strategies for review update (2008) (Continued)

\author{
22 evaluat\$.tw. \\ 23 controlled before.tw. \\ 24 exp pretest-posttest design/ \\ 25 exp quasi-experimental studies/ \\ 26 or/13-25 \\ 2712 and 26 \\ 28 limit 27 to $y r=$ “2003 - 2007”
}

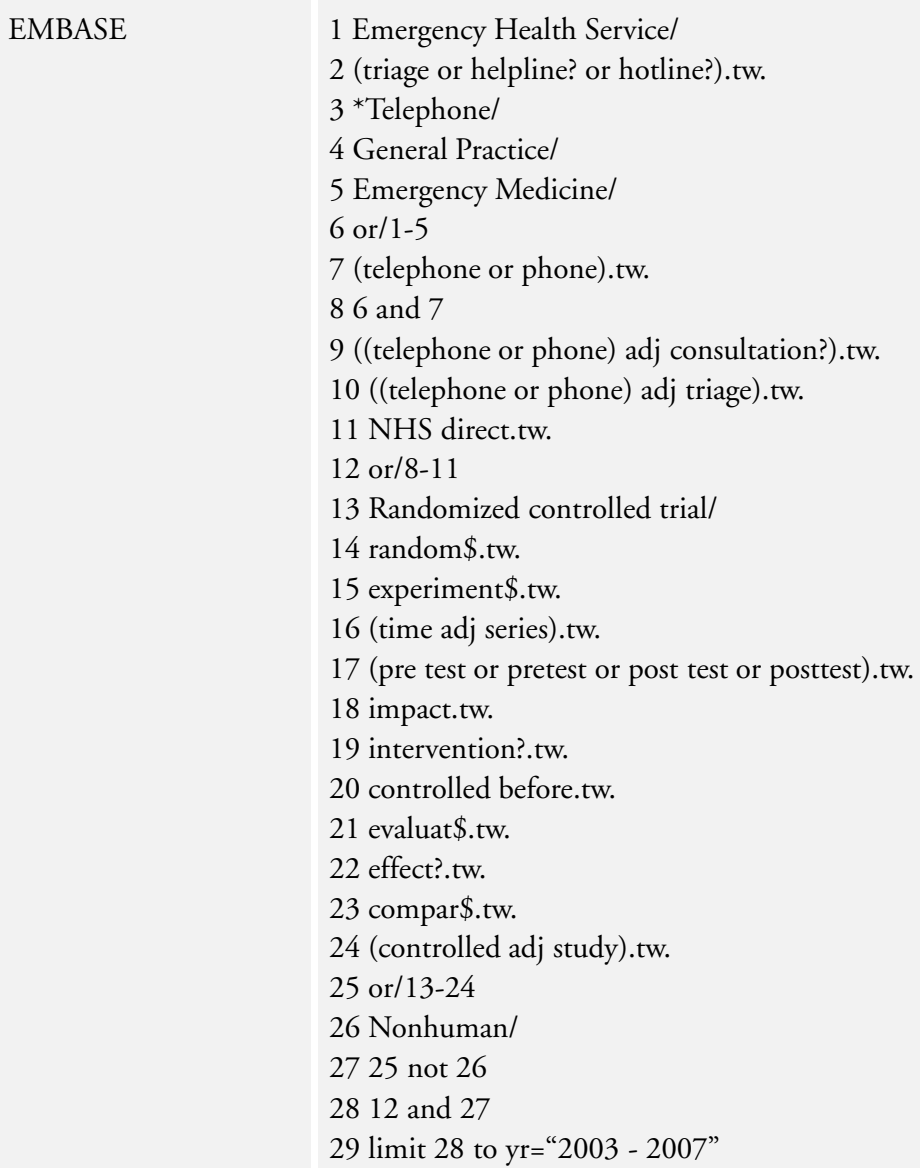

CENTRAL and DARE \#1MeSH descriptor Education, Continuing, this term only \#2EDUCATION* near (PROGRAM* ${ }^{*}$ or INTERVENTION* ${ }^{*}$ or MEETING* or SESSION* or STRATEG*) \#3(BEHAVIOUR or BEHAVIOR) near INTERVENTION*

\#4MeSH descriptor Pamphlets, this term only \#5(LEAFLET* OR BOOKLET* OR POSTER OR POSTERS) \#6(WRITTEN or PRINTED or ORAL) next INFORMATION \#7FACILITATOR*

\#8ACADEMIC next DETAILING \#9CONSENSUS next CONFERENCE \#10PRACTICE next GUIDELINE* 
\#11MeSH descriptor Feedback, this term only

\#12(feedback:TI, $\mathrm{AB}$ or compliance:TI,AB or marketing:TI,AB or reminder*:TI,AB)

\#13ALGORITHM*:TI,AB

\#14OUTREACH:TI,AB

\#15(opinion or education* or influential) next leader*

\#16CHART next REVIEW*

\#17COUNSEL*:TI,AB

\#18MeSH descriptor Reminder Systems, this term only

\#19MeSH descriptor Patient Education, this term only

\#20INFORMATION* near CAMPAIGN

$\# 21$ (effect* ${ }^{*}$ or impact or records or chart*) near audit

\#22PROMPTER* OR PROMPTING

\#23RECALL near SYSTEM*

\#24TRAINING next PROGRAM*

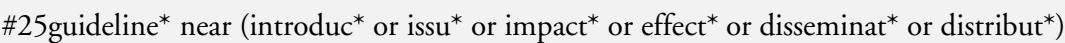

\#26MeSH descriptor Reimbursement Mechanisms explode all trees

\#27“FEE FOR SERVICE”

\#28MeSH descriptor Capitation Fee, this term only

\#29MeSH descriptor Deductibles and Coinsurance, this term only

\#30COST next SHAR*

\#31COPAYMENT*

\#32CO next PAYMENT*

\#33(PREPAY or PREPAID)

\#34PROSPECTIVE NEXT PAYMENT*

\#35MeSH descriptor Hospital Charges, this term only

\#36FORMULAR*

\#37MeSH descriptor Medicaid, this term only

\#38MeSH descriptor Medicare explode all trees

\#39BLUE next CROSS

\#40MeSH descriptor Nurse Clinicians, this term only

\#41MeSH descriptor Nurse Midwives, this term only

\#42MeSH descriptor Nurse Practitioners, this term only

\#43nurse next (rehabilitator* or clinician* or practitioner* or midwi*)

\#44MeSH descriptor Pharmacists, this term only

\#45CLINICAL next PHARMACIST*

\#46PARAMEDIC*

\#47MeSH descriptor Patient Care Team explode all trees

\#48team near (care or treatment)

\#49integrat* near (care or service*)

\#50case near (management or coordinat* or program* or continuity)

\#51MeSH descriptor Ambulatory Care Facilities explode all trees

\#52MeSH descriptor Ambulatory Care, this term only

\#53MeSH descriptor Home Care Services explode all trees

\#54MeSH descriptor Hospices, this term only

\#55MeSH descriptor Nursing Homes explode all trees

\#56MeSH descriptor Office Visits explode all trees

\#57MeSH descriptor Day Care, this term only

\#58MeSH descriptor Aftercare, this term only

Telephone consultation and triage: effects on health care use and patient satisfaction (Review) 
Table 1. Search strategies for review update (2008) (Continued)

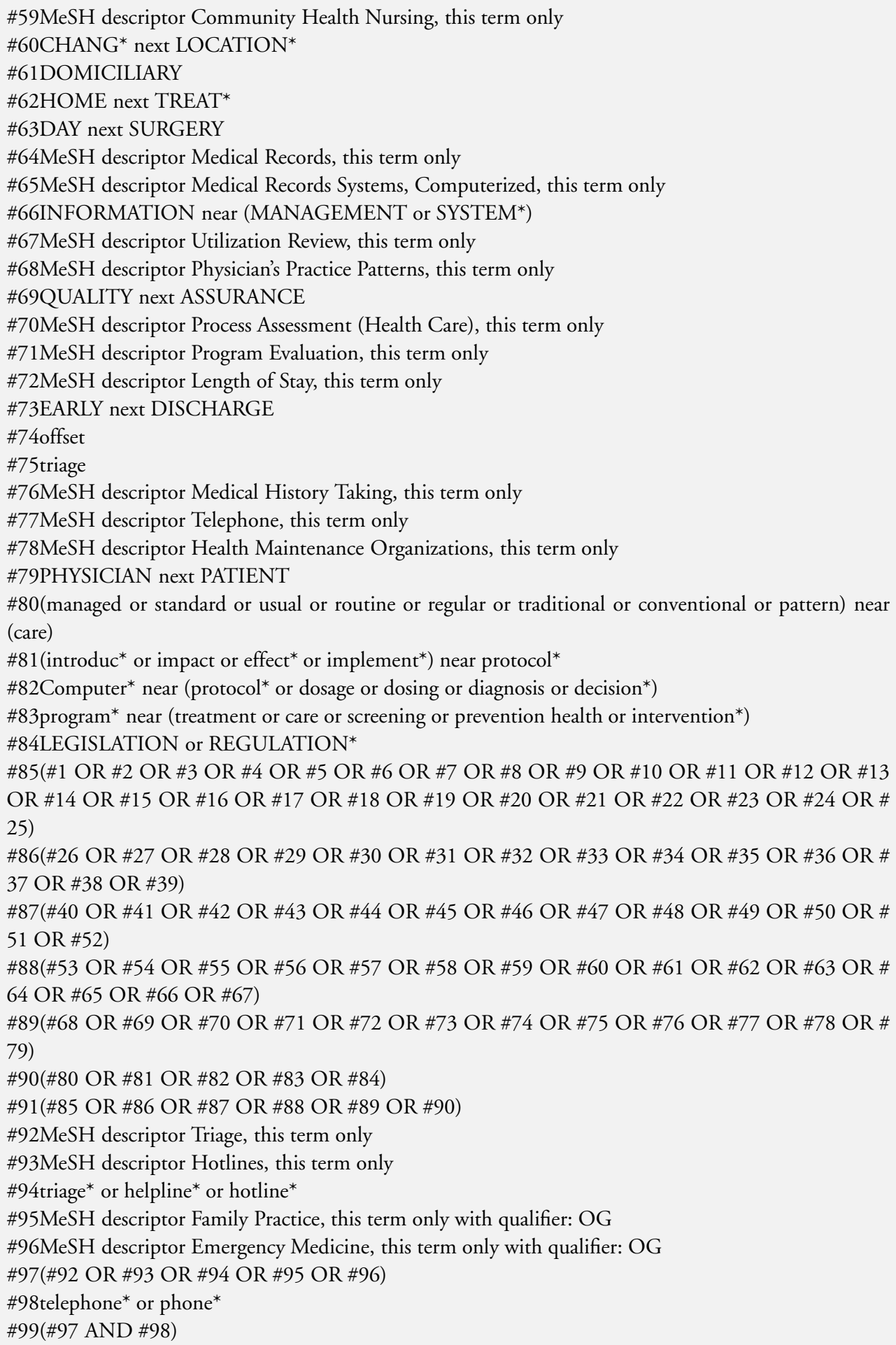


Table 1. Search strategies for review update (2008) (Continued)

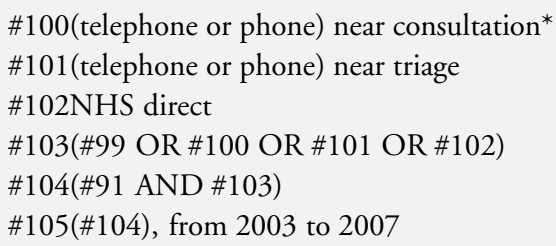

Table 2. Search strategies for review published in 2004

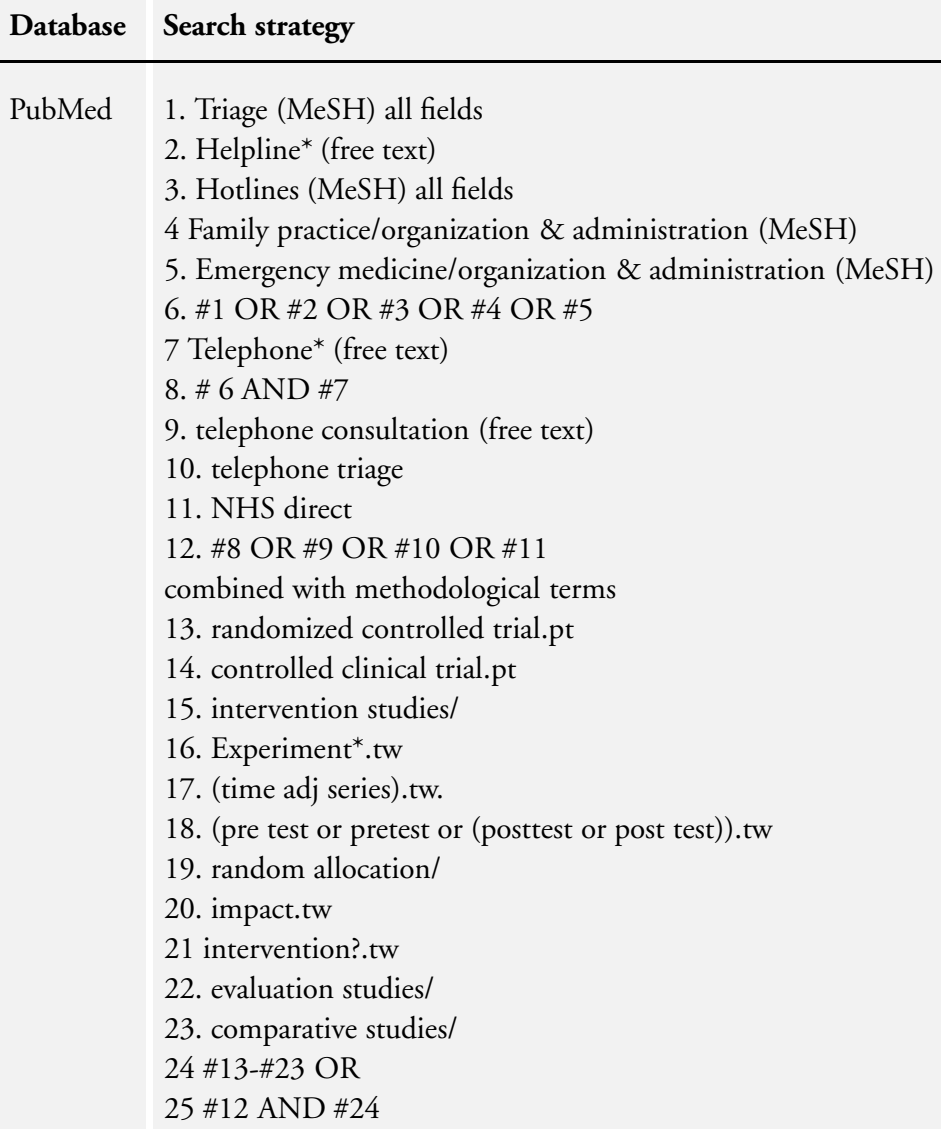

CCTR 1. triage (free text)

2. Hotlines $(\mathrm{MeSH})$

3. Helpline* (free text)

4. family practice $(\mathrm{MeSH})$

5. emergency medical services $(\mathrm{MeSH})$

6 \# 1 OR \#2 OR \#3 OR \#4 OR \#5

7 Telephone* (free text)

8) \#6 AND \#7

9) telephone consultation (free text)

10. telephone triage (free text) 
Table 2. Search strategies for review published in 2004 (Continued)
11. NHS direct
12. \#9 OR \#10 OR \#11
13.\#8 AND \#12
CINAHL 1. Triage (free text)
2. Helpline* (free text)
3. Hotline* (free text)
4. \#1 or \#2 or \#3
5. telephone* (free text)
6. \#4 AND \#5
7. Telephone consultation
8. telephone triage
9. \#7 or \#8
10. \#6 and \#9
methodological terms
11. clinical trial/
12. (controlled adj (study or trial)).tw
13. (randomised or randomized).tw
14. exp pretest-posttest design/ (MeSH)
15. exp quasi-experimental studies/ $(\mathrm{MeSH})$
16. comparative studies
17. time series
18. experiment*
19. \#11 or \#12 or \#13 or \#14 or \#15 or \#16 or \#17 or \#18
20. \#10 AND \#19

SIGLE 1. triage

2. telephone consultation

3. hotline*

4. helpline*

5. NHS Direct

6. \#1 or \#2 or \#3 or \#4 or \#5

EMBASE $\quad 1 *$ Emergency Health Service/

2 (helpline\$ or (help adj line\$)).

3 *Telephone/

$4 *$ General Practice/

$5 *$ Emergency Medicine/

$6 \# 1$ or $\# 2$ or \#3 or \#4 or \#5

7 telephone\$.mp.

8 \#6 and \#7

9 telephone consultation.mp.

10 telephone triage.mp.

11 NHS direct.mp.

$12 \# 8$ or \#9 or \#10 or \#11 


\section{WHAT'S NEW}

Last assessed as up-to-date: 14 February 2008.

\begin{tabular}{lll}
\hline Date & Event & Description \\
\hline 12 November 2008 & Amended & Minor changes \\
\hline
\end{tabular}

\section{H I S T O R Y}

Protocol first published: Issue 2, 2003

Review first published: Issue 4, 2004

\begin{tabular}{l|ll}
\hline Date & Event & Description \\
\hline 14 August 2008 & $\begin{array}{l}\text { New citation required but conclusions have not } \\
\text { changed }\end{array}$ & Searches updated in July 2007, no new studies. \\
\hline 12 June 2008 & Amended & Converted to new review format. \\
\hline 15 February 2008 & New search has been performed & No new studies \\
\hline 22 March 2004 & New citation required and conclusions have changed & Substantive amendment \\
\hline
\end{tabular}

\section{CONTRIBUTIONSOFAUTHORS}

FB wrote the protocol, developed and ran the search strategy, screened records for eligibility, extracted data, undertook the analysis and wrote the review. GB helped design the protocol, screened records for eligibility, extracted data and helped to write the review. SK helped to design the protocol and commented on the review.

\section{DECLARATIONSOF INTEREST}

None known. 


\section{SOURCES OF SUPPORT}

\section{Internal sources}

- University of Hertfordshire, UK.

\section{External sources}

- No sources of support supplied

\section{NOT E S}

The term telephone consultation is used in the review in preference to telephone triage as it indicates that call management options include providing information and advice and do not just include referral on to another health care professional.

\section{NDEX TERMS}

\section{Medical Subject Headings (MeSH)}

*Patient Satisfaction; Emergency Service, Hospital [utilization]; Family Practice [statistics \& numerical data]; Hotlines [utilization]; Primary Health Care [utilization]; Referral and Consultation [standards; *statistics \& numerical data]; Telephone ["statistics \& numerical data]; Triage [* methods; standards]

\section{MeSH check words}

Humans 